- Department :ommerce

onal Bureau

tandards

\title{
Computer Science and Technology
}

NBS Special Publication 500-73

Computer Model

Documentation

Guide

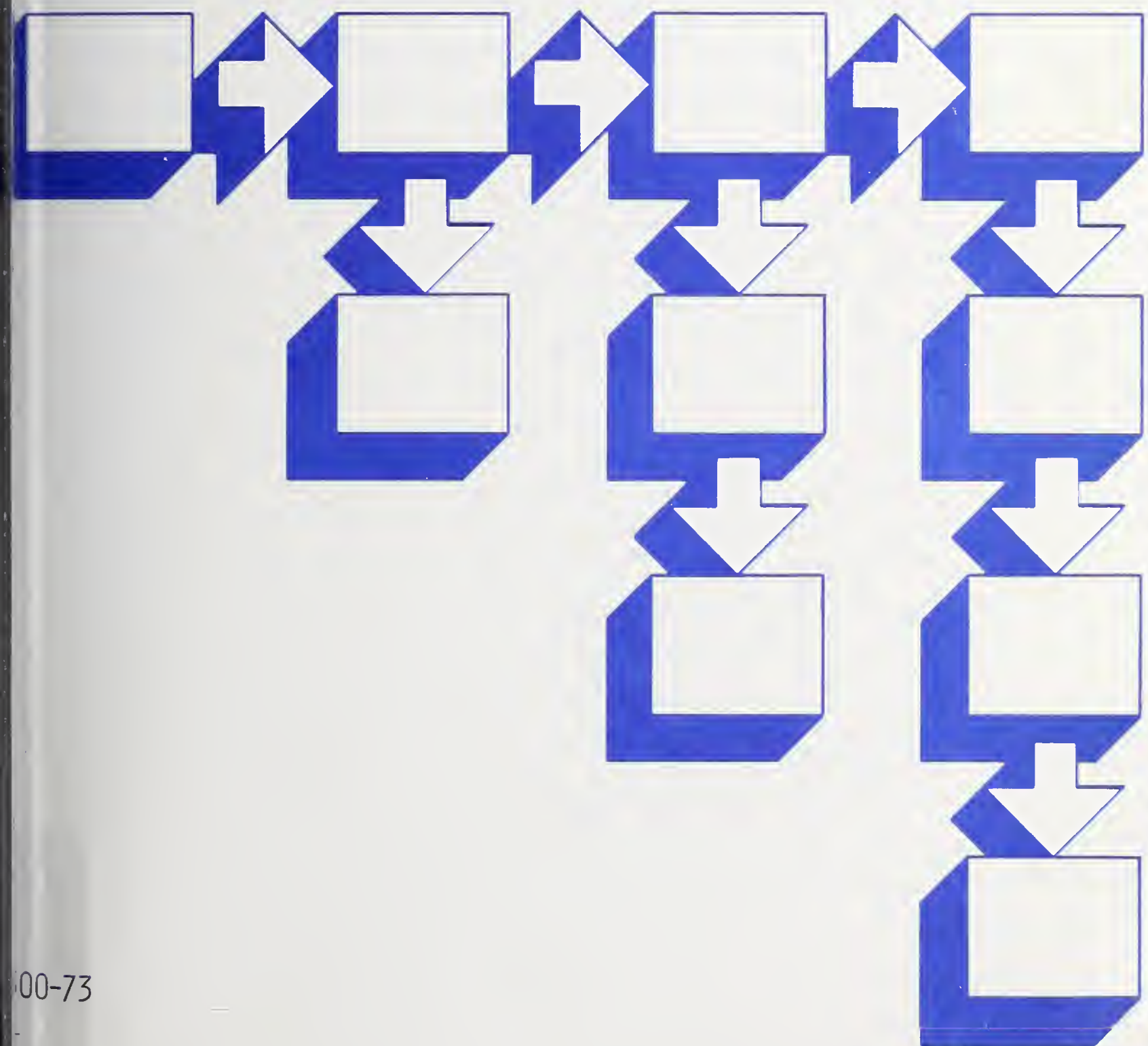


The National Bureau of Standards' was established by an act of Congress on March 3, 1901. The Bureau's overall goal is to strengthen and advance the Nation's science and technology and facilitate their effective application for public benefit. To this end, the Bureau conducts research and provides: (1) a basis for the Nation's physical measurement system, (2) scientific and technological services for industry and government, (3) a technical basis for equity in trade, and (4) technical services to promote public salety. The Bureau's technical work is performed by the National Measurement Laboratory, the National Engineering Laboratory, and the Institute for Computer Sciences and Technology.

THE NATIONAL MEASUREMENT LABORATORY provides the national system of physical and chemical and materials measurement; coordinates the system with measurement systems of other nations and furnishes essential services leading to accurate and uniform physical and chemical measurement throughout the Nation's scientilic community, industry, and commerce; conducts materials research leading to improved methods of measurement, standards, and data on the properties of materials needed by industry, commerce, educational institutions, and Government; provides advisory and research services to other Government agencies; develops, produces, and distributes Standard Relerence Materials; and provides calibration services. The Laboratory consists of the following centers:

Absolute Physical Quantities² - Radiation Research - Thermodynamics and Molecular Science - Analytical Chemistry - Materials Science.

THE NATIONAL ENGINEERING LABORATORY provides technology and technical services to the public and private sectors to address national needs and to solve national problems; conducts research in engineering and applied science in support of these efforts; builds and maintains competence in the necessary disciplines required to carry out this research and technical service; develops engineering data and measurement capabilities; provides engineering measurement traceability services; develops test methods and proposes engineering standards and code changes; develops and proposes new engineering practices; and develops and improves mechanisms to transfer results of its research to the ultimate user. The Laboratory consists of the following centers:

Applied Mathematics - Electronics and Electrical Engineering ${ }^{2}$ - Mechanical

Engineering and Process Technology $y^{2}$ - Building Technology - Fire Research —

Consumer Product Technology — Field Methods.

THE INSTITUTE FOR COMPUTER SCIENCES AND TECHNOLOGY conducts research and provides scientific and technical services to aid Federal agencies in the selection, acquisition, application, and use of computer technology to improve effectiveness and economy in Government operations in accordance with Public Law 89-306 (40 U.S.C. 759), relevant Executive Orders, and other directives; carries out this mission by managing the Federal Information Processing Standards Program, developing Federal ADP standards guidelines, and managing Federal participation in ADP voluntary standardization activities; provides scientific and technological advisory services and assistance to Federal agencies; and provides the technical foundation for computer-related policies of the Federal Government. The Institute consists of the following centers:

Programming Science and Technology-Computer Systems Engineering.

'Headquarters and Laboratories at Gaithersburg, MD, unless otherwise noted; mailing address Washington, DC 20234.

'Some divisions within the center are located at Boulder, CO 80303. 
NBS Special Publication 500-73

\section{Computer Model Documentation Guide}

Prepared by:

Federal Computer Performance Evaluation and Simulation Center

Washington, DC 20330

for the

Center for Programming Science and Technology Institute for Computer Sciences and Technology National Bureau of Standards Washington, DC 20234

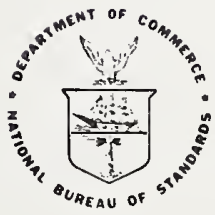

\section{U.S. DEPARTMENT OF COMMERCE} Philip M. Klutznick, Secretary

Jordan J. Baruch, Assistant Secretary for Productivity,

Technology and Innovation

National Bureau of Standards

Ernest Ambler, Director

Issued January 1981 


\section{Reports on Computer Science and Technology}

The National Bureau of Standards has a special responsibility within the Federal Government for computer science and technology activities. The programs of the NBS institute for Computer Sciences and Technology are designed to provide ADP standards, guidelines, and technical advisory services to improve the effectiveness of computer utilization in the Federal sector, and to perform appropriate research and development efforts as foundation for such activities and programs. This publication series will report these NBS efforts to the Federal computer community as well as to interested specialists in the academic and private sectors. Those wishing to receive notices of publications in this series should complete and return the form at the end of this publication.

National Bureau of Standards Special Publication 500-73

Nat. Bur. Stand. (U.S.), Spec. Publ. 500-73, 56 pages (Jan. 1981) CODEN: XNBSAV

Library of Congress Catalog Card Number: 80-600190 
This document was prepared for the Institute for Computer Sciences and Technology, National Bureau of Standards, by the Federal Computer Performance Evaluation and Simulation Center (FEDSIM). It is based on a similar document originally prepared for use by the U.S. Air Force in support of military analyses. That document has been rearranged, examples have been changed, and the document has been made more generaliy applicable so that it may be used throughout the Federal simulation community. Recommendations for 1mprovements of these guidelines are solicited. It is intended that after thorough reviews and trial use this document will be reissued as a Federal Guldeline in the series of Federal Information Processing Standards (FIPS). A11 comments should be directed to:

Institute for Computer Sciences and Technology Programming Science Division

Washington, D. C. 20234 
PREFACE

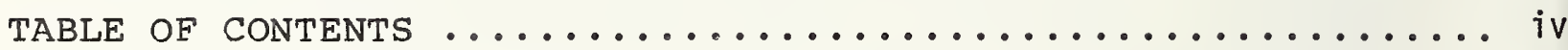

TABLES

FIGURES

ABSTRACT

Section

I. INTRODUCTION $\ldots \ldots \ldots \ldots \ldots \ldots \ldots \ldots \ldots \ldots \ldots \ldots \ldots \ldots \ldots \ldots \ldots$

II. GUIDELINES FOR PREPARING A MANAGEMENT SUMMARY MANUAL.. 4

1. Introduction ...................... 4

2. Model Description ..................... 4

3. Model Development and Experimentation ......... 7

4. Current and Additional Applications .......... 8

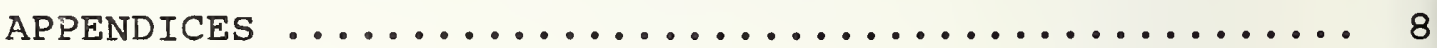

III. GUIDELINES FOR PREPARING A USER'S MANUAL .......... 9

1. Introduction ....................... 9

2. Description of the Model .................. 9

3. Model Input Data ........................ 17

4. Model Output Data ....................2

5. Run Preparation Instructions .............. 21

6. Sample Model Run ..................... 21

7. Trouble-Shooting Guide .................. 22

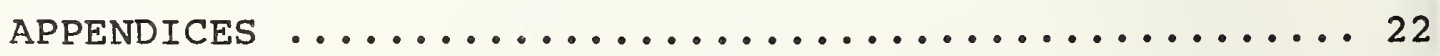

IV. GUIDELINES FOR PREPARING A PROGRAMMER'S MANUAL ...... 23

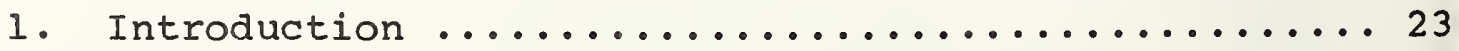

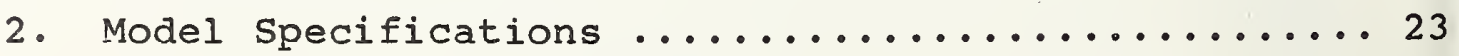




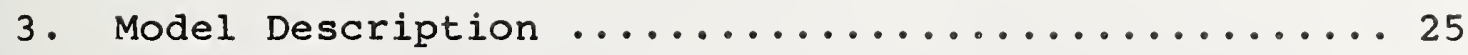

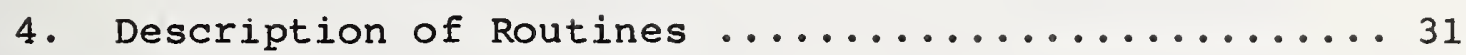

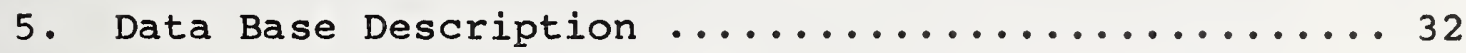

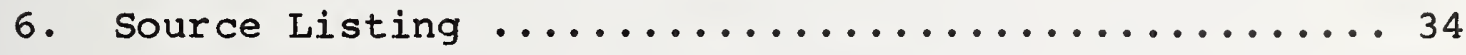

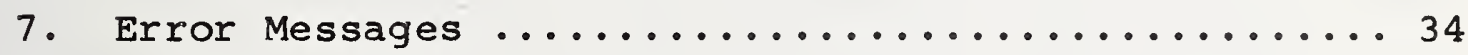

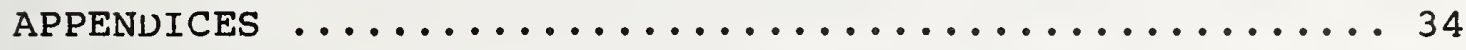

GUIDELINES FOR PREPARING AN ANALYST'S MANUAL ...... 35

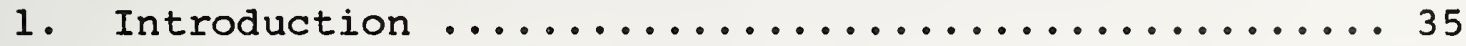

2. Functional Description of the Model .......... 35

3. Model Input and Output Data $\ldots \ldots \ldots \ldots \ldots \ldots$

4. Model Verification and Validation ........... 42

APPENDICES $\ldots \ldots \ldots \ldots \ldots \ldots \ldots \ldots \ldots \ldots \ldots \ldots \ldots \ldots \ldots \ldots \ldots \ldots \ldots \ldots$

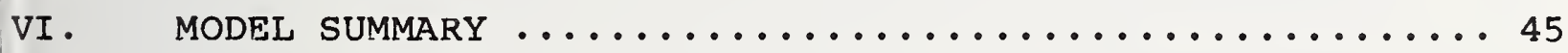

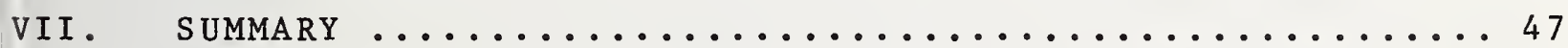

BIBLIOGRAPHY $\ldots \ldots \ldots \ldots \ldots \ldots \ldots \ldots \ldots \ldots \ldots \ldots \ldots \ldots \ldots \ldots \ldots \ldots \ldots$

TABLES

TABLE

IV-1 Cross-Referenced Data Structure List Sample ........ 28 IV-2 Sample List of Routines by Overlay Segment ....... 30 IV-3 Cross-Referenced Routine List Example .......... 33 


\section{FIGURES}

I -1 Recommended Table of Contents for a Management

Summary Manua $. . . . \ldots \ldots \ldots \ldots \ldots \ldots \ldots \ldots . . \ldots \ldots$

III-1 Recommended Table of Contents for a User's Manual ..... 10

III-2 Physical System Highlights Example ............. 12

III-3 Input/Output Schematic $\ldots \ldots \ldots \ldots \ldots \ldots \ldots \ldots \ldots \ldots$

III-4 Model Schematic Sample \#1 .................. 15

III-5 Model Schematic Sample \#2 .................. 16

III-6 Special Procedures Example ................... 19

IV-1 Recommended Table of Contents for a Programmer's

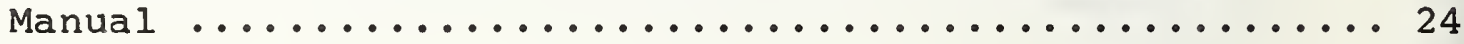

IV-2 Example of a Model Overview Block Diagram .......... 26

IV-3 Sample Overlay structure Diagram ................ 29

V-1 Recommended Table of Contents for an Analyst's

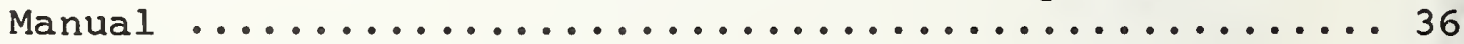

V-2 Modeled System Highlights Example .............. 37

V-3 Input/Output Schematic $\ldots \ldots \ldots \ldots \ldots \ldots \ldots \ldots \ldots$

V-4 Model Functional Flow Example ................ 41

V-5 Comparison of Actual and simulated Results ......... 44 
This document provides guidelines for preparing documentation for computer models. Recommended structures for four types of manuals providing model information for four different classes of audiences (managers, users, analysts, and programmers) is presented. This document specifies the content of sections and subsections for each type of manual. Manuals prepared using these guidelines will enable persons interested in a model to understand the capabilities and limitations of that model.

Key words: documentation; manuals; models; simulation.

\section{INTRODUCTION}

This draft document provides guidelines for preparing documentation for computer models, as well as complete submodels delivered separately. The primary goal of model documentation is to communicate effectively the details of model design and operation to persons with varying interests in a model. Since a model's developers are frequently not the model's ultimate users, complete, concise documentation is essential for effective model use. Documentation should inform analysts familiar with the phenomena being modeled, or the modeling techniques employed, of the essential features and assumptions of a new model. Throughout its life cycle, a model may be used and modified by various people, making accurate and current documentation of the underlying computer program essential for proper, correct use and maintenance of the model. Ultimately, model results may be used in a decision-making environment by individuals who are unfamiliar with the details of modeling and the associated benefits, risks, and costs. In such situations, model documentation should describe, in non-technical terms, the environment in which a model can be useful, limitations on its use, and the manpower, time, and dollar costs required by its use. These guidelines recommend structures and some conventions for preparing model documentation in the form of manuals for users, analysts, programmers, and managers. Each type of manual should provide clear, concise documentation that is directed toward an audience with a particular interest in a model. 
These guldelines devote a section to each type of manua 1, 1.e., The Manager's Manual, The User's Manual, The Programmer's Manual, The Analyst's Manual. Each section begins with a table of contents that lists recommended topics of interest to users of that manual. Items may be added to or deleted from this table of contents, however, according to individual requirements. The discussion for each manual enlarges upon the items required in each of the sections and subsections, as recommended in the table of contents for that manual. Terms used in each manual should be those directed toward that manual's audience.

These guidelines are for models that are used chiefly in a decision-making environment. Thus, the main goal of a Manager's Manual is to assist managers to make decisions. To accomplish this, the Manual must describe the model and its application to managers (Including the management that sponsored the model) who may be interested in using a developed capability. The Manual should provide managers with sufficient information to permit them to accurately assess model input requirements ( 1 ncluding time, money, and other resources), avaliable outputs, and the accuracy and precision of the results. Managers can use this Manual in justifying the employment of the model and in evaluating subsequent results.

A user is assumed to be interested mainly in deriving results from a model for specific applications. The guide1 ines recommend that the User"s Manual be organized Into a section for the user and a section for the data technicians who will set-up and run the model. To use the model inte1ligently, a user must be aware of 1 ts $l o g i c a l$ structure, the general simulation approach, and any assumptions and $11 \mathrm{mita}$ tions affecting the mode $1^{-} \mathrm{s}$ applicability. A user need not be interested in details of programming or analysis beyond the preparation of input data and the interpretation of model results.

Programmers are interested primarily in maintaining and modifying a model. A programmer must correct any errors discovered during model usage that are not attributable to user-entered data. Programmers, especially those required to convert a model to another computer system, need to understand features of a model that are installation unique. Thus, the Programmer's Manual must provide all the detalls necessary to understand the operation of a model: to debug 1t, to maintain and modify 1 , and to convert the model to other computer systems. 
These guidelines assume an analyst to be interested primarily in the analytical techniques and algorithms used in a model. An analyst is concerned with the equations used in a model and the methods used for model verification and validation. An analyst does not need to know user details such as input and output formats, or programming details involving language syntax.

Decisions about which of these manuals are actually required, whether or not they should be prepared in separate volumes, etc., should be made on a case-by-case basis. Also, a plan should be developed for documentation updates and maintenance, so that these manuals remain current. Such issues as these should be dealt with early during the model planning and development phases, so that documentation requirements actualiy become part of the development plan, rather than an afterthought. Further, applicable documentation produced using programing conventions should be used in conjunction with these guidelines.

Other guidelines prepared specifically to support computer software documentation are available which may be used in conjunction with this guideline. These documents are:

FIPS PUB 30, Software Summary for Describing Computer Programs and Automated Data Systems. It is used to announce computer programs which are transferable, and have broad applicability. A standard software summary form is defined ( $S F-185)$, which permits description of the program for identification, reference and dissemination. This form is used by the General Services Administration for registry of programs and for publication of program abstracts in the Federal Software Exchange Catalog.

FIPS PUB 38, Guidelines for Documentation of Computer Programs and Automated Data Systems. It provides guidance to documentation content for the development phase, including requirements documentation, system specifications, user, operations and maintenance manuals, and test documentation.

FIPS PUB 64, Guidelines for Documentation of Computer Programs and Automated Data Systems for the Initiation Phase. This document provides guidance for project requests, feasibility studies, and cost benefit analyses. 
This section provides a recommended structure for the Manager s Manual and describes the contents of each section and subsection. A manual prepared using these guidelines will provide descriptions of model capabilities and requirements such that model strengths and limitations will be communicated to decision makers and potential users. The Manager's Manual will provide managers with sufficient information to permit them to accurately assess model input requirements (including time, money, and other resources), available outputs, and the accuracy and precision of the results. Managers can use the Manager's Manual in justifying the employment of the model and in evaluating subsequent results. Figure II-l is a recommended table of contents for preparing a Manager's Manual. The sections and subsections included in that figure list suggested topics that are of interest to managers. Items may be added to or deleted from this table of contents, however, according to individual requirements.

\section{Introduction}

The introduction should identify the sponsoring organization, provide the background of the project, state the purpose of the model, and present an overview of the remaining sections in the manual. A common introduction used for other manuals prepared for a model may be used only if that introduction is void of specialized terms. The specific purpose of the Manager's Manual should be included in the introduction in a statement of the form:

"The purpose of this manual is to communicate to management the capabilities and limitations of (model name )."

\section{Model Description}

This section should provide a summary of model capabilIties and limitations. Use high-level block diagrams to clarify the narrative, as needed. 
1. Introduction

2. Model Description

2.1 Capabilities

2.2 Input/Output Classes

2.3 Assumptions and Limitations

3. Model Development and Experimentation

3.1 Development History

3.2 Verification and Validation

3.3 Model Experiments

3.4 Costs and Resource Requirements

4. Current and Additional Applications

4.1 Current Use

4.2 Additional Applications

APPENDICES
A. Project Documentation
B. Bibliography

RECOMMENDED TABLE OF CONTENTS FOR A MANAGEMENT SUMMARY MANUAL

FIGURE II-1 
This subsection should briefly summarize the capabilities of the mode1. Include highlights of mathematical and engineering concepts (but not equations) used as the basis of the mode1. Include a statement of the mode ${ }^{\prime} \mathrm{s}$ primary purpose. For example, "the model can be used to determine the dally number of machines in a job shop required to process the daily orders." Provide an overview of functional details that explains how the model accomplishes its stated purpose. Discuss the general areas of the model's applicability, Including the declsion making environments. For example, describe the types of systems and situations that can be simulated by the model (possibly with minor changes), including the number and kinds of subsystems that can be simulated. For example, if a job shop model includes order processing, machine repalr, or distribution subsystems, then their descriptions should be provided. Also include the relationship of this model to any other models ( $1 . e .$, another model may prepare input data for this mode1).

\subsection{Input/output c1asses}

Provide a short discussion on the different classes of input data required to drive the model and of output data generated by the model. For example, a job shop model might require entering the number of production centers, the number of machines per production center, the service rates of the machines, and the routing of the jobs (orders). Examples of model output include statistics that show the utilizations (percent busy time) of the production centers and the job turnaround (total processing) times. Identify any special preprocessing required for input data, as well as all post-processing required on model results.

\section{3 Assumptions and Limitations}

List assumptions and $11 m i t a t i o n s$ concerning the applicability of the model. Identify any restrictions on model usage caused by accuracy 1 imitations of input data and output quantities. Provide comments on levels of detall in the model that affect the mode1's applicability. For example, an analytical representation rather than a detalled simulation of a system component could affect model application. Also describe any use of random parameters that may affect the accuracy and use of model output. 
This section should describe significant model experiments already run and should provide details on model verification and validation procedures used. Include information on the model's development history resource costs and requirements, and use.

\subsection{Development H1story}

This subsection should provide pertinent details of the history of model development. Include comments on any alternative methods to computer simulation that were considered. Provide information on any "lessons learned" during model development, such as cost overruns, model development delays, user dissatisfaction with model results, insufficient workload data to support current and future model applications, inadequate model documentation, poorly defined problems, etc.

\subsection{Verification/Validation}

This subsection should describe any verification and validation procedures performed on the model. Include any analyses performed on the sensitivity of model output data to variations in model input data.

\section{3 Mode1 Experiments}

Describe significant model experiments performed and their results. Briefly describe the purpose of each experiment and the extent to which each experiment's goals were realized. Discuss the management decisions affected by each experiment. Discussion of major model experiments may be included in separate subsections (e.g., 3.3.1, 3.3.2).

\subsection{Costs and Resource Requirements}

This section should provide details on the costs and resource requirements of the model. Include the cost (in time and money) of collecting and validating input data. For example, long and costly data collection efforts may be necessary. Provide comments on model maintenance and experiment costs. Discuss job turnaround times (including typical run times) and peculiar model requirements such as abnormally large core requirements or long run times. Include comments on model portability and security requirements, as needed. 
This section should summarize benefits already derived from the model and recommend other applications for the mode 1 .

\subsection{Current Use}

This subsection should briefly describe how the model has been used by management in its decision-making process. Provide detalis of recommendations and conclusions derived using the model.

\subsection{Additional Applications}

This subsection should provide details of any additiona 1 applications and uses of the model beyond the current usage. Discuss in general terms any extensions and enhancements to the model which are feasible and could improve its utility. Identify any extensions which have been scheduled or planned.

\section{APPENDICES}

Two appendices should be provided as required. Appendix A should reference all other project documentation (including the User's Manual, Analyst's Manual, and Programmer s Manual), including references to the organization and person responsible for maintaining the document. Include references to any documentation of experiments performed using the model. Appendix B should list all applicable documents (excluding project documentation previously included in Appendix A), including cited and uncited references. 
III. GUIDELINES FOR PREPARING A USER'S MANUAL

This section presents a recommended User's Manual organizational structure and discusses the contents of sections and subsections to be included therein. A User ${ }^{\prime}$ Manual prepared using these guidelines will enable a nonprogramming model user to understand the mode1's logical structure, the input data requirements, the results produced by the model, and the use of model results. Figure III-1 presents a recommended table of contents for a User's Manua 1. The sections and subsections contained in the figure cover the general needs of a user interested in a model. In documenting a particular model, however, sections and subsections may be added to improve clarity, and some subsections may be omitted for simple models. Note that there is a certain amount of redundance among the various sections of a User's Manual prepared according to these guidelines. Nevertheless, the progressively increasing level of detall dictated by this structure is desirable to satisfy different levels of user interest in the manual.

\section{Introduction}

The User's Manual introduction should contain the background of the project, the purpose of the model, and an overview of the remaining sections in the manual. A common introduction may be used for all the manuals prepared for a mode1, but the specific purpose of the User's Manual should be included in a statement of the form:

"The purpose of this manual is to provide nonprogramming users of (model name) with the information necessary to use the model effectively."

2. Description of the Model

This section should contain a we11-structured presentation of the logical detalls of the model. The material here should be descriptive and include block diagrams and tables and charts where needed; it should not give details needed by a data technician to run the model.

2.1 Overview

This subsection should provide sufficient general information about the model to assist a user in determining the applicability of the model for specific needs. 
1. Introduction

2. Description of the Model

2.2 Overview

2.1.1 Moded Identification

2.1.2 Physical System Bighlights

2.1.3 Model Applicability

2.1.4 Input and output

2.2 Methodology
2.2.1 Physical System Details
2.2.2 Model Logie and Data Flow

2.3 Assumptions and Limitations

2.3.1 System-Related Assumptions and Limitations

2.3.2 Model Parameters

2.3.3 Output Iimitations

2.3.4 Restrictions on Model Ose

3. Model Input Data

3.1 General Description

3.2 Detailed Descriptions

3.2.1 Data Set Name (Pirst Data Set)

3.2 .1 .1 Number of Inputs

3.2.1.2 Other Related Data Sets

3.2.1.3 Description of Data Items

3.2.2.4 Sample Input

3.3 Data collection and Maintenance

3.3.1 Data Sources

3.3.2 Collection Procedures

3.3.3 Opdating Procedures

4. Model Output Data

4.2 General Description

4.2 Detailed Description

4.2.1 Data Set Name (Pirst Data Set)

4.2.1.1 Description of Items

4.2.1.2 Interpretation

4.2.1.3 Sample Output

5. Run Preparation Instructions

5.1 Run-Stream Description

5.2 Resource Requirements

5.3 Restart/Recovery Procedures

6. Sample Model Run

7. Trouble-sbooting Guide

APPENDICES
A. List of Abbreviations and Acronyms
B. Glossary
c. Bibliography

RECOMMENDED TABLE OF CONTENTS FOR A OSER'S MANUAL

FIGURE III-I 
2.1.1 Model Identification The identification should contain the name of the physical system being simulated, name of the mode 1 (acronym and expansion), programming language(s) used to implement the model, computer(s) on which the model may be run, and relationships, if any, to other models.

2.1.2 Physical System Highlights. Include a block diagram that shows the physical system or phenomenon being simulated. Discuss, at a macro level, the major system elements shown in the diagram, their relation to each other, and the flow of control, information, data, and activity between them, as appropriate. In the case of complex models, provide in this subsection a first-level block diagram that shows the major subsystems and their interactions, and postpone the details of each of the subsystems until subsection 2.2.1. Figure III-2 is an example of physical system highlights depicting the operations of a typical shop model.

2.1.3 Model Applicability. Discuss the general magnitude of model applicability. The types of systems or situations that can be simulated by the model (possibly with minor changes) and the number of subsystems (e.g., production centers and machines per production center in a job shop simulation) that can be handled are examples of material to be included in this subsection.

2.1 .4 Input and Output. Provide a general statement of the different kinds of input data needed to drive the model, the output data generated by the model, and uses of model output. For example, a job shop model might require entering the number of production centers, the number of machines per production center, the service rates of the machines, and the routing of the jobs (orders). Examples of model output include statistics that show the utilizations (percent busy time) of the production centers and the job turnaround (total processing) times. The principal model use could be to determine the number of machines in a job shop required to process the daily orders.

Highlight any special data collection procedures (e.g., run other models or computer programs, extract data from documents or listings, conduct sampling experiments) required to produce mode1 input data. List any unique data sources or other organizations that might have to be contacted to gather data. Figure III-3 is an example of an input/output schematic. 


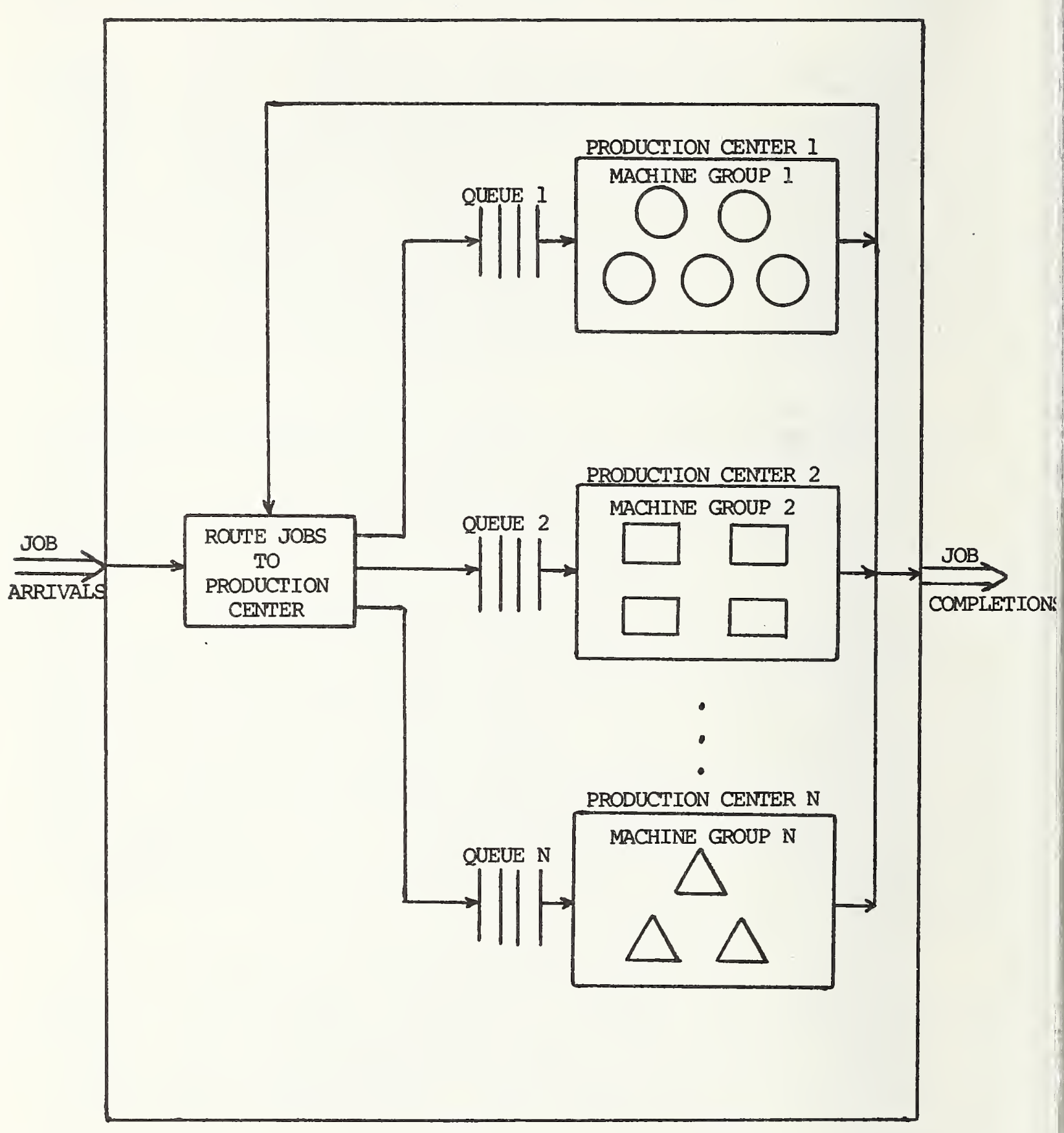

PHYSICAL SYSTEM HIGHLIGHTS EXAMPLE

FIGURE III-2 


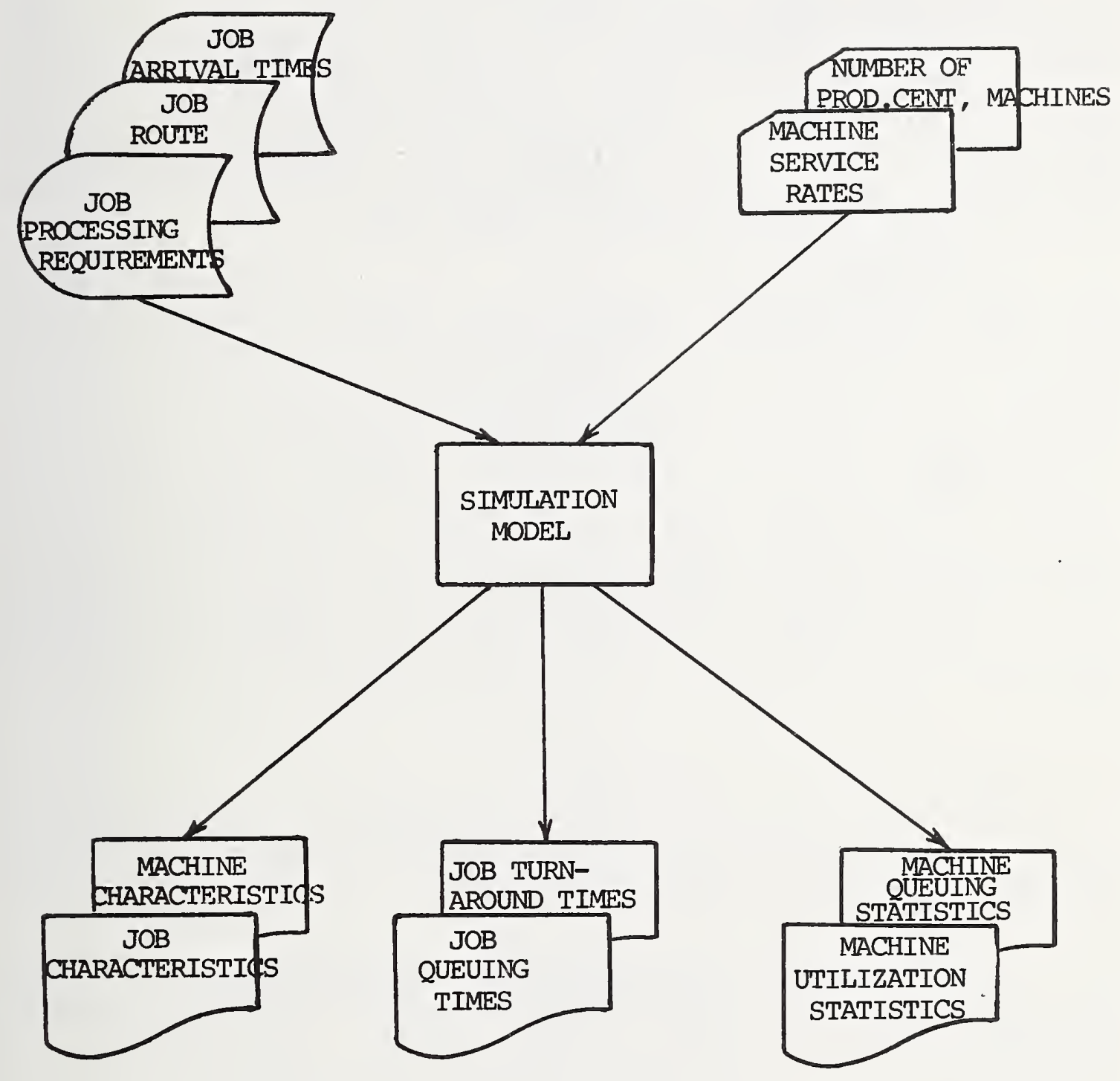

INPUT /OUTPUT SCHEMATIC

FIGURE III-3 
This subsection should provide the user with a detailed understanding of how the model works.

2.2.1 Physical System Details. This subsection is an elaboration of subsection 2.1.2. The operations that take place in each of the blocks in the Physical system Block Diagram should be discussed in detail. Detailed block diagrams of subsystems should be provided for a complex model. The level of detail used in the simulation (e.g., the smallest meaningful time increment for event-type models, the way in which complex system interactions are simplified in the model) should be clearly indicated.

2.2.2 Model Logic and Data Flow. This subsection should describe the logical flow of data through the model, from the entry of input data to the generation of output data. Include a schematic that indicates the major model software elements, the data flow between model elements, and model inputs and outputs. Figures III-4 and III-5 are two types of schematics for the same model. Either of these two types, or any other type of schematic that clearly depicts model logic and data flow, may be used. Accompanying discussion should relate model elements and data flow to physical system elements and data flow described in Section 2.1.2. For complex models, include a table that relates physical system names to the program segments that simulate them.

\subsection{Assumptions and Limitations}

Al1 the system-related assumptions, assumptions on mode 1 parameters (e.g., hard-coded values), limitations on output accuracy, and any restrictions on the use of the model should be discussed in detail.

2.3.1 System-Re1ated Assumptions and Limitations. List any assumptions that limit or describe the kinds of systems or phenomena that are treated in the model. For example, a description of a job shop model should define the mode $1^{\prime}$ s boundaries (i.e., the subsystems that the model includes), the kinds of activities simulated (e.g., machine failures and repairs), etc.

2.3.2 Mode1 Parameters. List the valid ranges for principal model input parameters (e.g., the maximum and minimum number of subsystems). Also 1 ist values for any parameters that are included in the model software and cannot be modified by the user. 


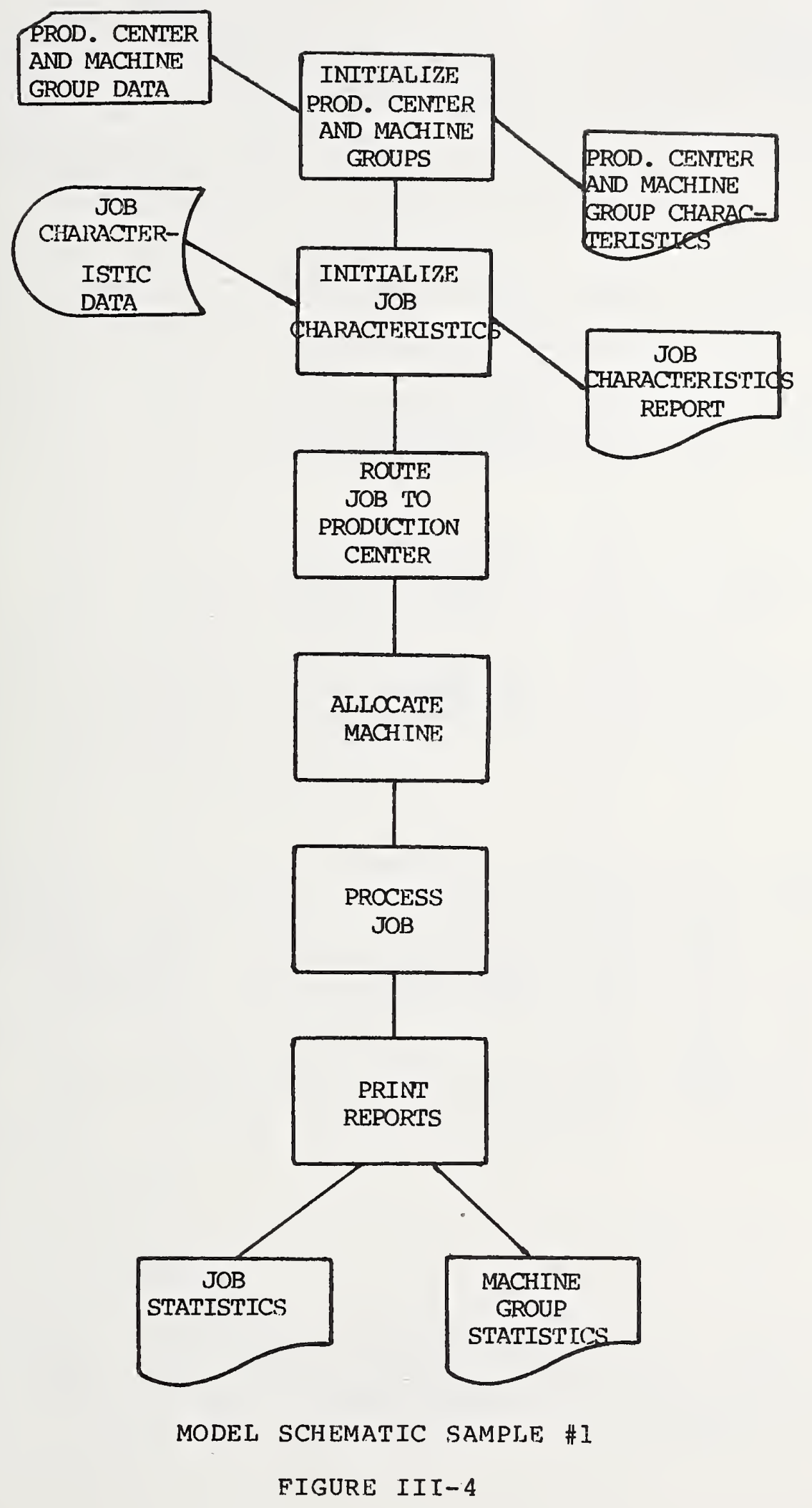




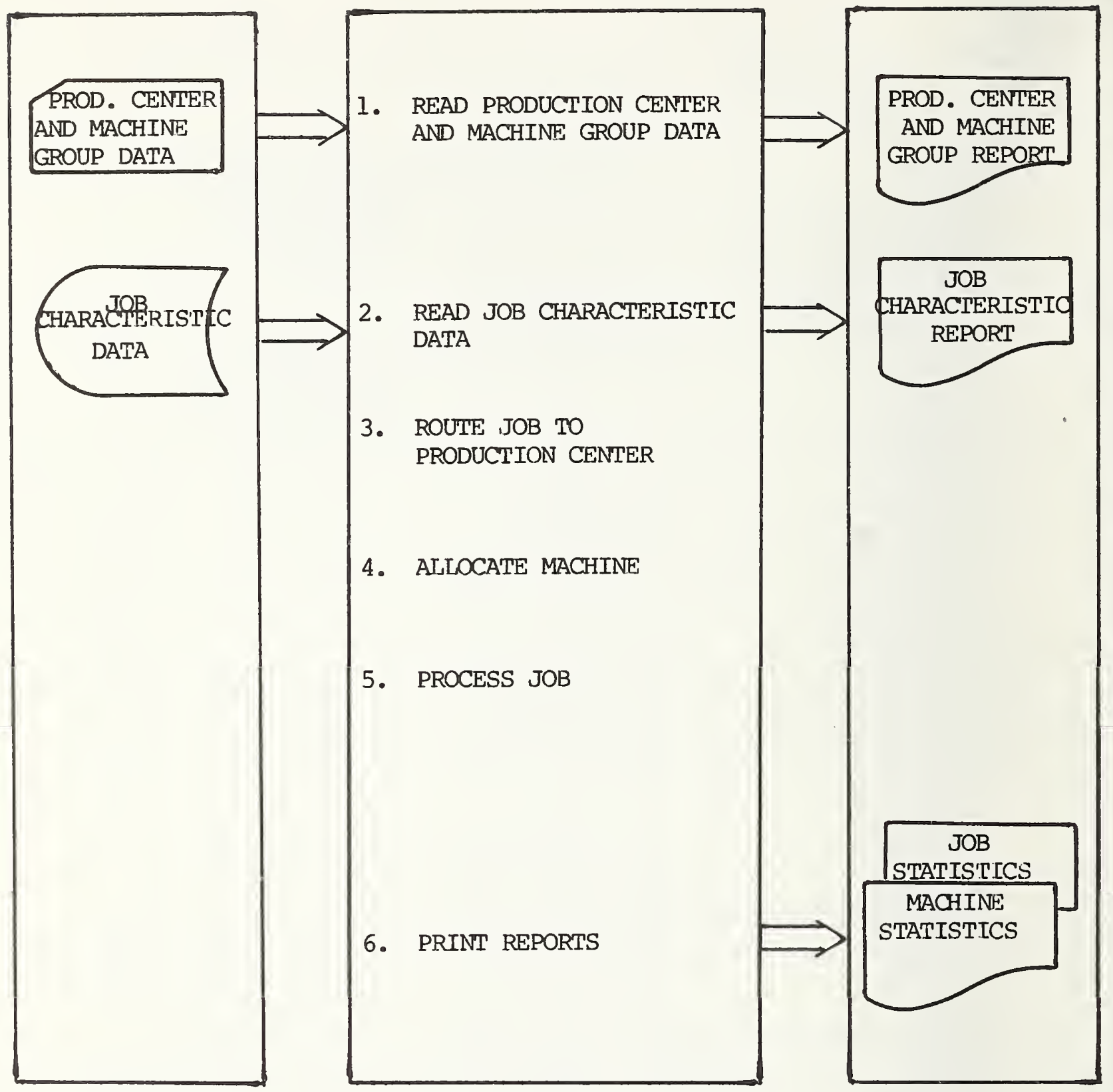

MODEL SCHEMATIC SAMPLE \#2

FIGURE III-5 
2.3.3 Output Limitations. List any limitations on output usage caused by inaccuracy of the output data. For example, all digits in an output data field may not be significant because the input data are estimates, and high precision in the output data is either unobtainable or inappropriate.

2.3.4 Restrictions on Model Use. Enumerate all restrictions on model usage. For example, a job shop model restriction might be that only first-in, first-out queuing disciplines are modeled for the production centers.

\section{Model Input Data}

This section should describe in detall all the input data needed to run the model. The material in this and the four subsequent sections should serve as a reference for both the user and the data technician who runs the model.

\subsection{General Description}

This subsection should describe the overall input data structure and the data media (tape, cards, disk data sets, etc.). Include a table that shows input data set names, their media, and any general data limitations. Also, describe the interdependence, if any, of input data sets. (Detalled descriptions of individual data items within the input data sets should be left for Section 3.2.)

3.2 Detalled Descriptions

Input data items are normally organized in related groups, such as machine performance characteristics, job processing requirements, etc., or as the data items that are entered on one punch card. These related groups of data establish and define a data set and should be described together. The input data sets and the items within each data set should be discussed in the order of their appearance in the run stream. For each input data set, provide the following information (each data set description should begin on a new page).

3.2 .1 Data Set Name.

In this subsection, give an overview of the data set's contents and its purpose.

3.2.1.1 Number of Inputs. Indicate the number of data sets of this type and the maximum number of data items in the data set that may (or must) be used in the simulation. Discuss any factors that influence the total number of inputs from this data set. 
3.2.1.2 0ther Related Data Sets. List any data sets whose contents depend on or dictate the input values for this data set. Discuss the relationships between data 1 tems in the data sets.

3.2.1.3 Description of Data Items. In this subsection, provide general comments on the format of the data 1 tems (e.g., free form, integer in card columns 8-11, NAMELIST) followed by the description of each of the data 1tems. For each 1tem, the following should be given: name, type, format ( 1 f fixed), permissible range or fixed value, unit of measurement, default value (value assumed by the program when the 1tem is omitted), definition of the item describing how it is used in the model, relationship to other data items. Tables should be used where appropriate.

\section{2 .1 .4 Sample Input.}

A format layout should be provided for the data set to provide the user a visual reference for preparing the input data.

\subsection{Data Collection and Malntenance}

An lmportant part of model application is data collection. Therefore, $1 t$ is necessary to include appropriate $1 \mathrm{n}-$ structions on data collection and maintenance. Specific responsibilities need to be assigned to analysts and users for these functions.

3.3.1 Data Sources. Discuss the data sources for each input data set. The discussion should identify the form in which raw data are avallable, other organizational elements from which the data must be collected, if appropriate, and the time required to collect the data.

3.3.2 Collection Procedures. Describe any special statistical techniques or experiments for obtaining the data. Identify any other computer programs or models that must be used to collect or process data, and 11 st or reference instructions for their use. Where approprlate, include a flowchart that 11lustrates the major data collection steps and their sequence. Figure III-6 is an example of special procedures to be used in obtaining data for a model. In this example, the type and frequency of orders are analyzed along with production center performance data to produce a statistical data base. This. data base $1 \mathrm{~s}$ then used as Input to a model 


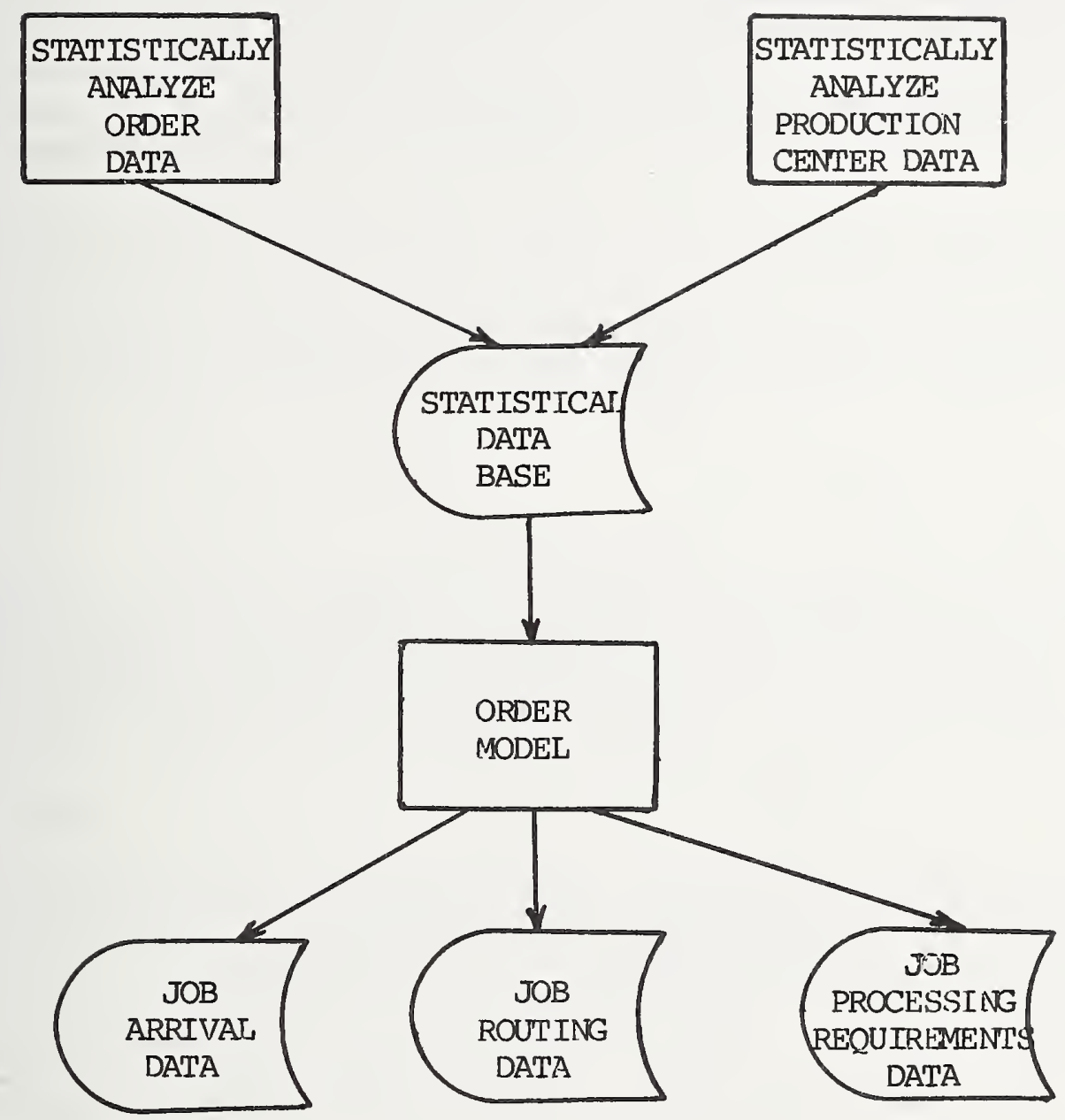

SPECIAL PROCEDURES EXAMPLE

FIGURE III-6 
of the order handling process.

The order model produces data that profiles the arrival patterns, routing distributions, and processing requirements of the jobs. These data are, in turn, used as input to the job shop model.

3.3.3 Updating Procedures. Give step-by-step procedures for maintaining the data sets and preparing them for new experiments. Identify any other computer programs that must be used to update the data sets, and list or reference instructions for their use. Where appropriate, include a flowchart that lilustrates the major update procedures and their sequence.

\section{Model Output Data}

This section should describe in detall all the output data produced by the model and should indicate their meanings and uses.

\subsection{General Description}

Discuss the overall output structure in this section. Indicate the number and types of output data sets, output media, correlation between outputs, quantity of output (optional and mandatory), and postprocessing, if any, that should be performed on the output data.

\subsection{Detailed Description}

For each output data set (or major group of logically connected data items), provide the following information (each output data set should begin on a new page).

4.2.1 Data Set Name. Give the full name or acronym of the output data set or group of data under this subheading. Give an overview of the data set's contents, its purpose, and its relation to other model results.

4.2.1.1 Description of Items. Each output 1tem should be included 1 a table that shows its name, a brief description, and gives information to use in validity checking, if appropriate. Accompanying discussion should expand on each item"s description and should show how the items are derived or calculated. Include mathematical formulae where appropriate.

4.2.1.2 Interpretation. Explain how the data 1 tems can be used, and describe actions to be taken for any subsequent runs based on the output. 
4.2.1.3 Sample Output. Include a sample of the output data set. A sample format is satisfactory where it is not practical to provide an actual sample.

5. Run Preparation Instructions

This section of the User's Manual should describe procedures for organizing the input data to submit computer runs as discussed in section 3 .

5. 1 Run-Stream Description

This subsection should give a pictorial (or tabular) representation of the deck constituting the run-stream that shows all the control cards and the data cards in proper sequence. Mandatory and optional cards should be discussed. If the model is interactive, include comments on any special techniques used for interactive submission of jobs.

\section{2 Resource Requirements}

This subsection should describe the computer resources required by the model. These include main memory, mass storage, number of tape units, execution time, numbers of punched cards, and printed lines expected as output. If the computer resources vary depending on input data, provide aids to estimate them.

5.3 Restart/Recovery Procedures

For models that require large amounts of computer resources it is important to recover from abnormal terminations and to restart the job. If any such provisions are made in the model design, they should be discussed in this subsection.

6. Sample Mode1 Run

Include a sample run that illustrates the complete input scenario and the resulting output to assist a beginning user in making a test run and verifying correctness of procedures. 
7. Trouble-Shooting Guide

Tabulate user input error-messages produced by the model software, and describe the required corrective action. Since other errors should be handled by programmers, those errors should be discussed in the programmer's manual.

\section{APPENDICES}

Three appendices should be provided as required. Appendix A should provide an alphabetical listing of all abbreviations and acronyms used in the User"s Manual. Appendix B should list all specialized User's Manual terms and their definitions. All applicable documents, including cited and uncited references, should be provided in Appendix C. 
This section provides a recommended organization for a Programmer's Manual and describes the contents of each section and subsection proposed for that manual. A Programmer s Manual written using these guidelines will enable a programmer to maintain and modify a model. The guidelines will provide all the details necessary for a programmer to understand the operation of the model and to trace through it for debugging, for making modifications, and for determining if and how the model can be converted to other computer systems. Figure IV-l is a recommended table of contents for a Programmer"s Manual. The sections and subsections included in the figure cover the general needs of a programmer interested in a model. In documenting a particular model, however, sections and subsections may be added to improve clarity, and some subsections may be omitted for simple models. Any appropriate documentation produced using a program documentation language could be used to satisfy the guidelines contained herein.

1. Introduction

The introduction to the Programmer's Manual should contain the background of the project, the purpose of the model, and an overview of the remaining sections in the manual. A common introduction may be used for all the manuals prepared for a model, but the specific purpose of a Programmer"s Manual should be included in a statement of the form:

"The purpose of this manual is to provide programmer personnel of (model name) with the information necessary to effectively maintain and modify the model."

\section{Model Specifications}

This section should provide a summary of the model's specifications, including capabilities (i.e., problems addressed and methods of solution), a description of the host computer system, and the processing requirements ( $1 . e$. , memory, peripherals, languages) placed by the model on that host system. The details should be presented in tabular form (supplemented by narrative description, as appropriate), whereby one table describes the complete modeling system and additional tables describe major submodels or programs as needed for clarity. 
1. Introduction

2. Model Specifications

3. Model Description

3.1 Processing

3.1 .1 Overview

3.1.2 Major Components

3.1.3 Model Initialization and Wrap-up

3.2 Data Structures

3.2.1 Local Data Structures

3.2.2 Global Data Structures

3.2.3 Special Data Structures

3.3 Overlays

3.4 Model Modifications

3.4.1 Planned Maintenance

3.4.2 Other Changes

4. Description of Routines

4.1 Routine Name (First Routine)

4.1.1 Purpose

4.1.2 Type

4.1.3 Calling Sequence

4.1.4 Argument Definition

4.1.5 Calling Routines

4.1.6 Called Routines

4.1.7 Files

4.1.8 Error Messages

4.1.9 Narrative

4.1.10 Block Diagrams

4.1.11 Sample Test Run

5. Data Base Description

5.1 File Name (First File)

5.1 .1 Purpose

5.1 .2 Format

5.1 .3 Routines

5.1 .4 Updating

6. Source Listing

7. Error Messages

APPENDICES
A. Glossary
B. Bibliography
c. Index
D. Model Test Results

RECOMMENDED TABLE OF CONTENTS FOR A PROGRAMMER'S MANUAL

FIGURE IV-1 
This section should contain a well-structured presentation with emphasis on the operational details of the model. The discussion should be written in an easy-to-understand manner that cross-references special model 1 anguage terms with modeled system features whenever possible. This section should be divided into four subsections.

\subsection{Processing}

This subsection should provide details on model operations for programmers who need to understand the processing techniques used in the model. The discussion should be at the Macro level, with a discussion of internal routine details postponed until Section 4 of this manual. Details on I/O formats and default input data values should be reserved for the User's Manual. Block diagrams should be used as necessary to supplement the narrative.

3.1.1 Overview. This subsection should present, in modeled system terminology, an overview of the problem solved by the mode1. Include a discussion of the basic tasks modeled. Figure IV-2 is an example of a block diagram that could supplement a narrative description in this subsection.

3.1.2 Major Components. This subsection should describe the flow of data or control information through the model at the major routine, or routine group, level. Include detailed block diagrams that depict paths among the modeled tasks, highlighting major decision points in the logic flow. This subsection may contain as many levels of discussion as are necessary to clearly describe model operation.

3.1 .3 Model Initialization and Wrap-Up. This subsection should note any differences in the performance of mode 1 tasks accomplished during model initialization and wrap-up and those same tasks when performed during normal processing.

\subsection{Data Structures.}

This subsection should provide information on all data structures internal to the model. Include descriptions of local and global variables, arrays, and data sets, as we 11 as any special data structures, such as the set-entity relationships in SIMSCRIPT. If required for understanding, separate descriptions of each array index should be provided. 


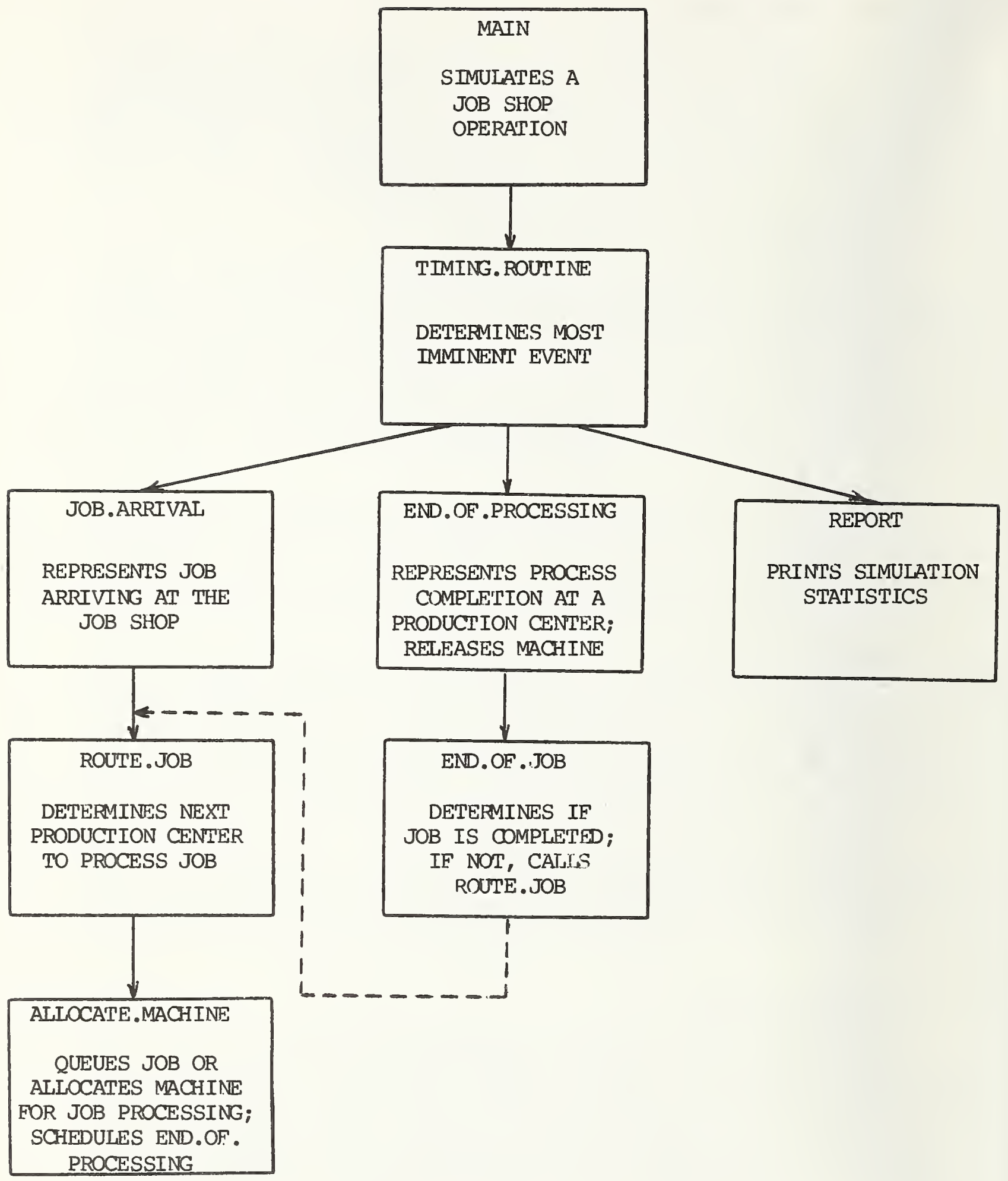

EXAMPLE OF A MODEL OVERVIEW BLOCK DIAGRAM

FIGURE IV-2 
3.2.1 Local Data Structures. This subsection should contain the meaning and purpose of all local variables, arrays, and data sets (local data structures have their values defined only within particular routines). To improve clarity, local data structures should be associated with the routines in which they appear.

3.2.2 Global Data Structures. This subsection should contain the meaning and purpose of all global variables, arrays, and data sets (global data structures are defined throughout the model). Include an alphabetized list of global data structures (including special data structures), cross-referenced by the routines in which they appear, and the source code line numbers (Table IV-1). Source code line numbers $c$ an be obtained from the source listing in Section 6 of this manual. Examples of global data structures that should be included in this subsection are the COMMON blocks of FORTRAN.

3.2.3 Special Data Structures. Any special data structures, both local and global, should be listed and described in this subsection. For example, a job shop model implemented in SIMSCRIPT might represent the jobs with temporary entities, the job processing requirements with entity attributes, and the sequence of production centers required to process the job with a set (owned by the job with production centers as numbers). A GPSS implementation, however, might represent the jobs with transactions, the processing requirements with transaction parameters, and the route with a row in a matrix save value (the columns contain the sequence of production centers).

3.3 Overlays

If the model is overlayed, this subsection should provide detalls of the overlay design decisions that determined the overlay strategy. Included should be a narrative and a block diagram description of the control flow of the overlays and their interactions. Figure IV-3 contains a sample overlay structure with a main program, four primary overlay segments, and five secondary overlay segments. Routines residing in each overlay, and their memory requirements, should be listed (Table IV-2). References should be made to the discussion of model processing in this manual (Subsection 3.1) to reinforce or clarify the overlay discussion. 


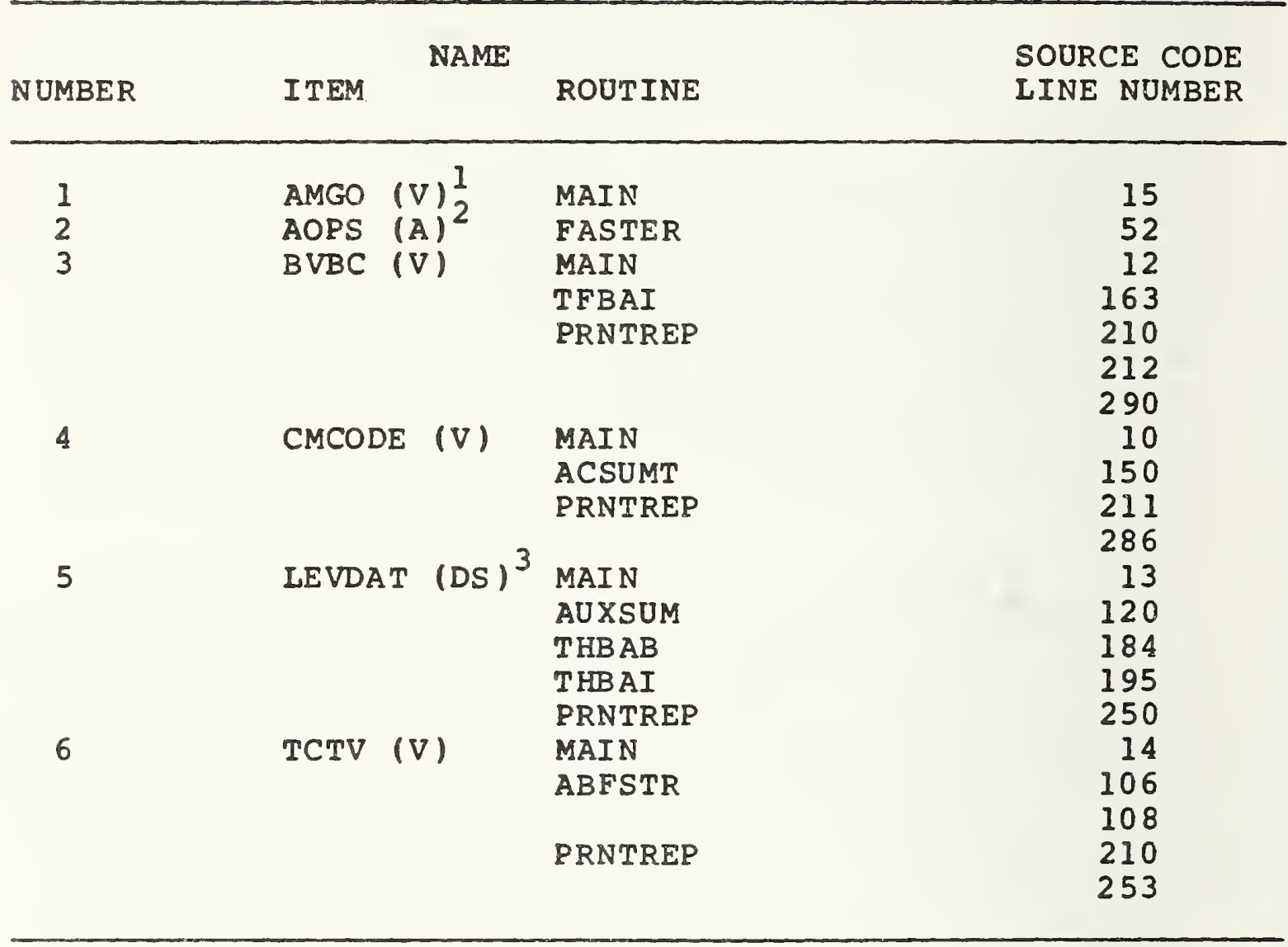

\footnotetext{
${ }^{1}$ Item is a variable.

2 Item is an array.

3. Item is a data set.
}

CROSS-REFERENCED DATA STRUCTURE LIST SAMPLE

TABLE IV- I 


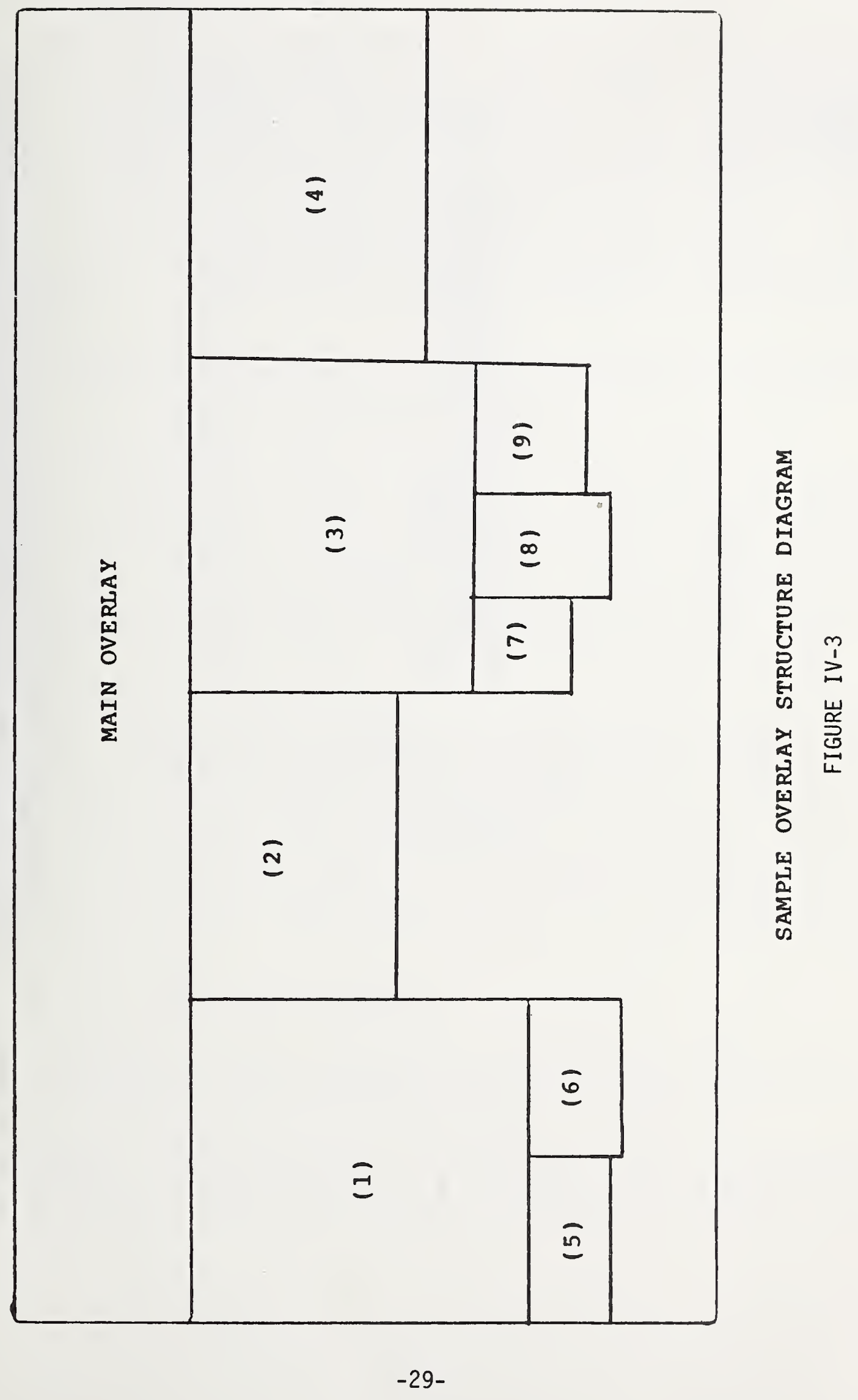




\begin{tabular}{|c|c|c|c|}
\hline $\begin{array}{l}\text { OVERLAY } \\
\text { SEGMENT NUMBER }\end{array}$ & & $\begin{array}{l}\text { ROUTINE } \\
\text { NAME }\end{array}$ & $\begin{array}{c}\text { MEMORY } \\
\text { REQUIREMENTS } \\
\text { (KBYTES) }\end{array}$ \\
\hline \multirow[t]{4}{*}{1} & & MAIN & 50 \\
\hline & & ROUTI & 10 \\
\hline & & ROUT2 & 20 \\
\hline & & ROUT 3 & 20 \\
\hline \multirow[t]{3}{*}{2} & & PROCl & 100 \\
\hline & & PROC 2 & 25 \\
\hline & & PROC 3 & 25 \\
\hline \multirow[t]{2}{*}{3} & & COMPI & 75 \\
\hline & & COMP 2 & 50 \\
\hline \multirow[t]{2}{*}{4} & & SOLVI & 75 \\
\hline & & SOLV 2 & 50 \\
\hline \multirow[t]{3}{*}{5} & & LS IGNI & 100 \\
\hline & 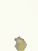 & LS IGN 2 & 20 \\
\hline & & LS IGN 3 & 15 \\
\hline 6 & & COMPIO & 140 \\
\hline \multirow[t]{2}{*}{7} & & FINDI & 70 \\
\hline & & FIND2 & 48 \\
\hline 8 & & SUM10 & 140 \\
\hline 9 & & WRITER & 137 \\
\hline 10 & & REPORT & 128 \\
\hline
\end{tabular}

SAMPLE LIST OF ROUTINES BY OVERLAY SEGMENT

TABLE IV -2 
This subsection should include information concerning changes in model software and data bases. Include a description of any programming conventions used in the model (e.g., all variables referencing one data base may begin with a specific character). In addition, this subsection should provide procedures needed by programmers during the model compilation, recompilation, and execution stages. Include a sample control card setup that 111 istrates each of those states, including mandatory and optional cards. If the model is interactive, include comments on interactive procedures.

3.4.1 Planned Maintenance. This subsection should identify a 11 planned periodic maintenance on the model and its data bases (e.g., periodic data base updates).

3.4.2 Other Changes. This subsection should identify procedures for making all modifications to the model other than planned periodic maintenance. Provide detalls for making changes necessitated by programming errors discovered during model usage, as we 11 as changes to the model required by changes in the host modeling language. Include directions for implementing software changes to produce a new version of the model (e.g., changes in model applicability).

4. Description of Routines

This section should provide a detalled description of principal model routines. Include a discussion of all types of routines that comprise the model ( $1 . e \cdot$, event, subroutine, function, etc). Provide an alphabetized listing of all routine names along with calling routines and called routines ( $\mathrm{Table}$ IV-3) or a block diagram showing routine linkages, as needed. Each routine should be described in a separate subsection. For each routine, provide the following information.

\subsection{Routine Name (First Routine)}

4.1.1 Purpose. Briefly state the purpose of the routine (e.g., routine ALLOCATE computes the time a job is scheduled to complete its processing at a production center).

4.1.2 Type. Specify the type of routine (i.e., function, subroutine). A description of all routine types in the model should be contained in the introductory comments of this section. 
4.1.3 Calling Sequence. List al1 variables, arrays, pointersinthe routine calling sequence.

4.1.4 Argument Definition. Define all routine arguments.

4.1 .5 Calling Routines. List all routines that call this routine.

4.1 .6 Called Routines. List all routines called by this routine.

4.1.7 Files. List all files this routine creates or uses.

4.1.8 Error Messages. Itemize a11 error messages which can originate in this routine.

4.1.9 Narrative. Include a narrative description as necessary, to ampify and highlight subtleties included in the code. As a minimum, include any equations and formulae referenced from the Analyst's Manual.

4.1.10 Block Diagrams. Use block diagrams or other documentation aids (such as program documentation languages), as required, to clearly depict operation of the routine.

4.1.11 Sample Test Run. Provide the results of test runs, along with values of input data, for each complex routine to assist in verifying changes to those routines.

5. Data Base Description

This section should discuss all mass storage files used or created by the model. Each file should be described in a separate subsection and should contain the following information (each file description should begin on a new page).

5.1 File Name (First File) files.

Provide the full name or acronym of al1 the model

5.1 .1 Purpose. Briefly state the purpose of the file (e.g., contains preprocessed destination data).

5.1.2 Format. Explain the format of the file (i.e., block, size, record size, data item identification, and field sizes). 


$\begin{array}{ll}1 & \text { ABFSTR } \\ 2 & \text { ACSOMT } \\ 3 & \text { AOXSUM } \\ 4 & \text { FASTER } \\ 5 & \text { MAIN } \\ 6 & \text { PRNTREP } \\ 7 & \text { TFBAI } \\ 8 & \text { THBAB } \\ 9 & \text { THBAI }\end{array}$

NONE

TEBAI

THBAB

ACSOMT

ABFSTR

AOXSOM

FASTER NONE

PRNTREP

THBAI

PRNTREP

\section{CROSS-REFERENCED ROOTINE IIST EXAMPLE}

TABLE IV - 3 
the file.

5.1 .4 Updating. Include instructions for file maintenance and updating as appropriate.

6. Source Listing

This section should contain the source code of the mode1. If the source 11 sting is large, it should be bound separately and made avallable upon request. Also, source $118 t 1 n g s$ with 1 ine numbers can be referenced from subsection 3.2 .2 as a cross-reference for model variables.

7. Error Messages

Al1 program-generated error messages, the names of the routines in which they are generated, and suggested corrective actions should be listed in this section. Each error message may be described in a separate subsection.

\section{APPENDICES}

Four appendices to this manual should be provided as required. Appendix A should define all terms in the Programmer's Manual not defined elsewhere in the document. A I Ist of applicable documents, lncluding cited and uncited references, should be provided in Appendix B. Appendix C should provide an alphabetized index that gives the page on which each subject contalned in the Programmer's Manual may be found. If the Programmer's Manual is divided Into more than one volume, the index in the first volume should be the index of the volumes. The index in each of the remaining volumes should reference only those subjects within that volume. Appendix D should provide a listing of model test results along with values entered into the model that produced those results. Include any Interim model outputs necessary to understand the final outputs. Provide analyses of model results as necessary. 
This section presents a recommended organization for an Analyst's Manual and describes the contents of each section and subsection to be included in that manual. An Analyst's Manual prepared using these guidelines will enable an analyst to understand a mode1's functional structure, the algorithms used in the model, and techniques employed for model verification and validation. Figure $v-1$ contains a recommended table of contents for an Analyst's Manual. The sections and subsections included cover the general needs of an analyst interested in a model. In documenting a particular mode1, however, sections and subsections may be added to improve clarity, and some subsections may be omitted for simple mode $1 \mathrm{~s}$.

1. Introduction

The introduction to the Analyst's Manual should contain the background of the project, the purpose of the model, and an overview of the remaining sections in the manual. A common introduction may be used for all the manuals prepared for a model, but the specific purpose of the Analyst's Manual should be included in a statement of the form:

"The purpose of this manual is to provide nonprogramming analysts of (model name) with the details of the algorithms used in the model and the techniques employed for model verification and validation."

2. Functional Description of the Model

This section should contain a we11-structured presentation with emphasis on the functional details of the model. The discussion should be written in an easy-to-understand manner that, whenever possible, avoids the use of highly specialized terms. The section should be divided into four subsections.

2.1 Overview

This subsection should provide a functional description of the model in sufficient detall for an analyst to understand the salient system features that were modeled. Functional flow charts and other graphics should be used to enhance the narrative. Include a statement of the kind of model ( $1 . e$., discrete-event model that simulates jobs entering a job shop at arbitrary points in time, being routed through a predetermined sequence of production centers, and being processed at the production centers) and the degree to

which the model portrays the real world system. Figure V-2 is an example of modeled system highlights. Included should 
1. Introduction

2. Functional Description of the Model

2.1 Overview

2.2 Detailed Methodology

2.3 Assumptions and Iimitations

2.3.1 Stochastic Assumptions

2.3.2 Magnitude Limitations

2.3.3 Critical Values

2.4 Model Flexibility

3. Model Input and Output Data

3.1 Input Data

3.2 Output Data

4. Model Verification and Validation

4.1 Verification Techniques

4.2 Validation Considerations

APPENDICES
A. Glossary
B. Bibliography

RECOMMENDED TABLE OF CONTENTS

FOR AN ANALYST'S MANUAL

FIGURE V-I 


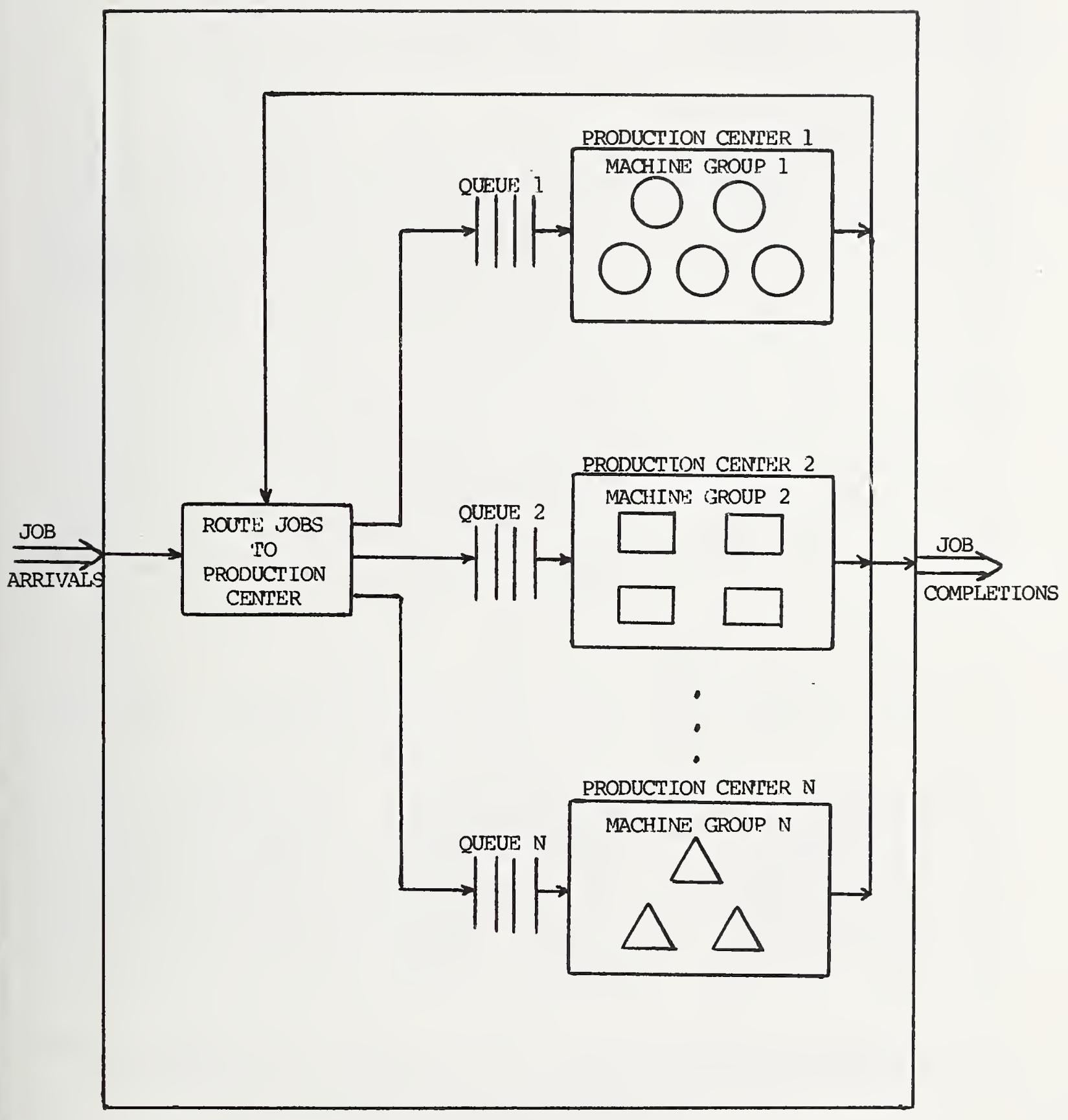

MODELED SYSTEM HIGHLIGHTS EXAMPLE

FIGURE $\quad \mathrm{V}-2$ 
be the set of model responses (output) produced by a given set of model input data. Figure $V-3$ provides an example of the types of model input and output. For additional detalls on model description, the analyst should be directed to the appropriate section of the User"s Manual for this model.

\subsection{Detailed Methodology}

This subsection should provide the functional details for analysts to understand the algorithms and equations used in the model. We1l-known mathematical equations (and formulae) should be clearly identified and references should be cited for their derivation. For example, in a job shop model the queuing discipline simulated for each production center should be stated. Include the derivation for extensions of known results or for the development of new analytical techniques. Special complicating detalls, such as the use of precalculated data for job arrival times should be stated. The description must be detailed enough to demonstrate how the model uses the input data to calculate output information. Functional flow charts and graphs should be used to enhance the narrative descriptions of each algorithm. Figure $V-4$ is an example of a model functional flow chart. This section should include a subsection for each major algorithm or set of equations.

\subsection{Assumptions and Limitations}

This subsection should 1 ist all model assumptions and all factors that affect or limit model output use. The following items should be included as appropriate.

2.3.1 Stochastic Assumptions. In this subsection, itemize a11 stochastic assumptions that affect mode1 output accuracy. For example, the treatment of certain random variables in a simplistic manner, by using only their mean values and not sampling from a statistical distribution, should be described in this subsection. Each stochastic item should be described in a separate subsection (e.g., 2.3.1.1, 2.3 .1 .2 ).

2.3.2 Magnitude Limitations. This subsection should include all limitations on the size of the problems the model can 


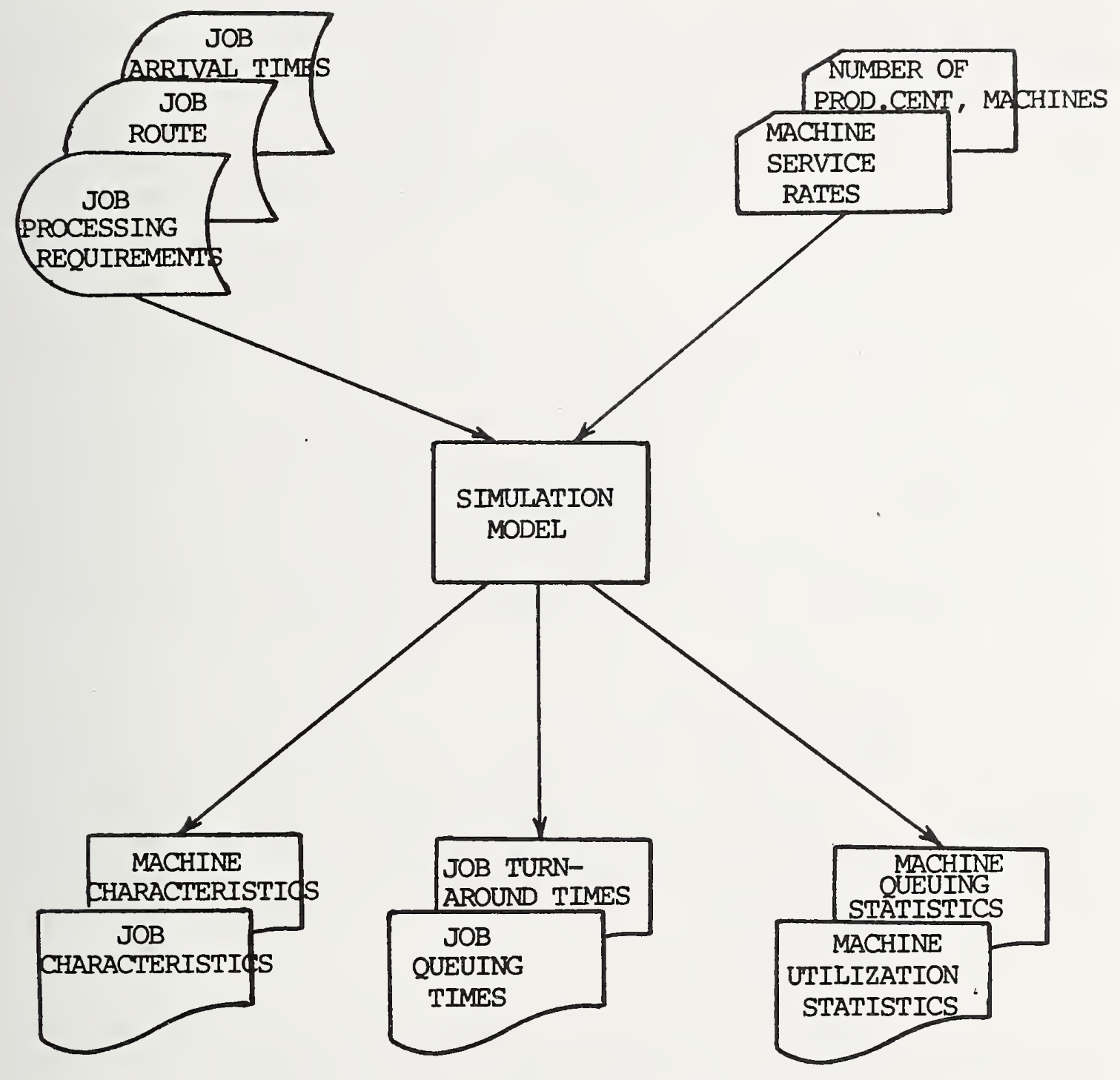

INPUT/OUTPUT SCHEMATIC

FIGURE V-3 
address. For example, the current dimensions of certain arrays in a model may limit the number of activities that can be represented in that model. Each limitation should be described in a separate subsection.

2.3.3 Critical Values. This subsection should identify critical input data values to which model outputs are sensitive. Many elements that have a range of values will have one value that is particularly significant to the analyst. This may be a breakpoint, a minimum stock level, or a critical job rate, etc. Each critical value should be described in a separate subsection (e.g., 2.3.3.1,2.3.3.2, etc.).

\section{4 Mode1 Flexibility}

This subsection should address the capability of adapting the model to changing requirements, such as anticipated physical system operational changes, interacting with new or improved models, and planned periodic changes. An example of a flexible design is one that facilitates the addition of a machine failure and repair subsystem to a job shop model. Model components and procedures designed to be flexible shall be clearly identified. Factors that affect model flexibility are the familiarity of the analyst with the model, the model's size, its complexity, and its data structures. Subsections should be used as required.

3. Model Input and Output Data

This section should discuss the categories of input data and the accuracy of model output data. The material contained in the next two subsections will enable the analyst to assure the existence of the data necessary to execute the model and to ascertain the accuracy of the data generated by the model.

\section{I Input Data}

Identify all categories of input data and any special analytical techniques required to obtain those data. If the sources of input data include output from other models, provide sufficient details to enable an analyst to assess the appropriateness of those data in solving his problem. For example, if the arrival rate of jobs is provided by a separate model of the order handling process, the analyst needs to determine that the simulated ordering process 


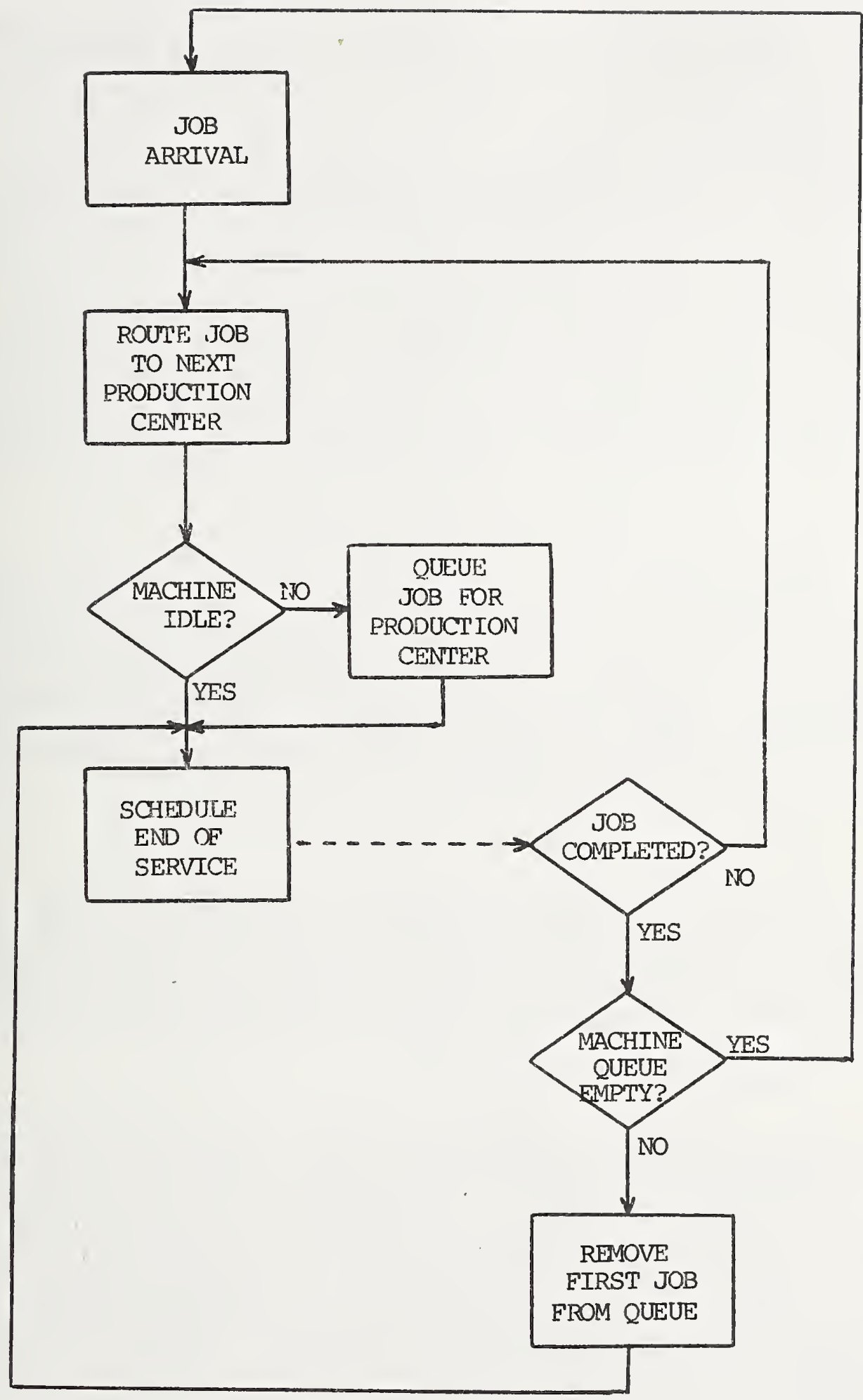

MODEL FUNCTIONAL FLOW EXAMPLE

FIGURE V-4 
corresponds to the one existing in his job shop. Details on input data types and formats should be reserved for the User's Manual.

3.2 Output Data

This subsection should provide the analyst with a methodology for assessing the accuracy of model output data. Since the accuracy of the output values will be judged in relating to the method used to derive them, a review of the algorithms used to compute those output values may be neces sary at this point. Describe in detail any corrective actions to be taken by an analyst in case of inaccurate output values, (i.e., Should the analyst contact a programmer for a program change or have a user modify the input data deck to correct the problem?). Subsections may be used as required.

4. Model Verification and Validation

This section of the Analyst's Manual should describe the methodology used to verify and validate the model. Model verification (sometimes referred to as software validation) is concerned with the compatibility of the model's programmed structure to the analyst's design and with model debugging. Model validation provides the analyst, and user, with the confidence that the model provides a good representation of the modeled system.

4.1 Verification Techniques

This section should provide an analyst with concise procedures by which the model was verified. Each equation included in Section 2.2 of the Analyst's Manual should be verified and cross-referenced to the Programmer's Manual for this model. Include all other verification techniques used.

\subsection{Validation Considerations}

This section should provide an analyst with the description of any procedures that were used to ensure that the model is an "accurate" abstraction of the real system. Any methodology used to determine how well the model represents the real system should be presented in this section. While complete confidence in a model may be impossible, a good validation procedure can increase the amount of confidence an analyst has in a model. Figure V-5 is an example of a graph that could be used in a model validation procedure. 
Two appendices to this manual should be provided as required. Append1x A should define all terms in the Analyst's Manual not defined elsewhere in the document. Appendix B should provide a list of applicable documents and a bibliography designed for use by system analysts. 
FREQUENCY DISTRIBUTION OF JOB TURHAROUHD TIMES COAPARISOH OF ACTUAL AHD SIMULATED RESULTS

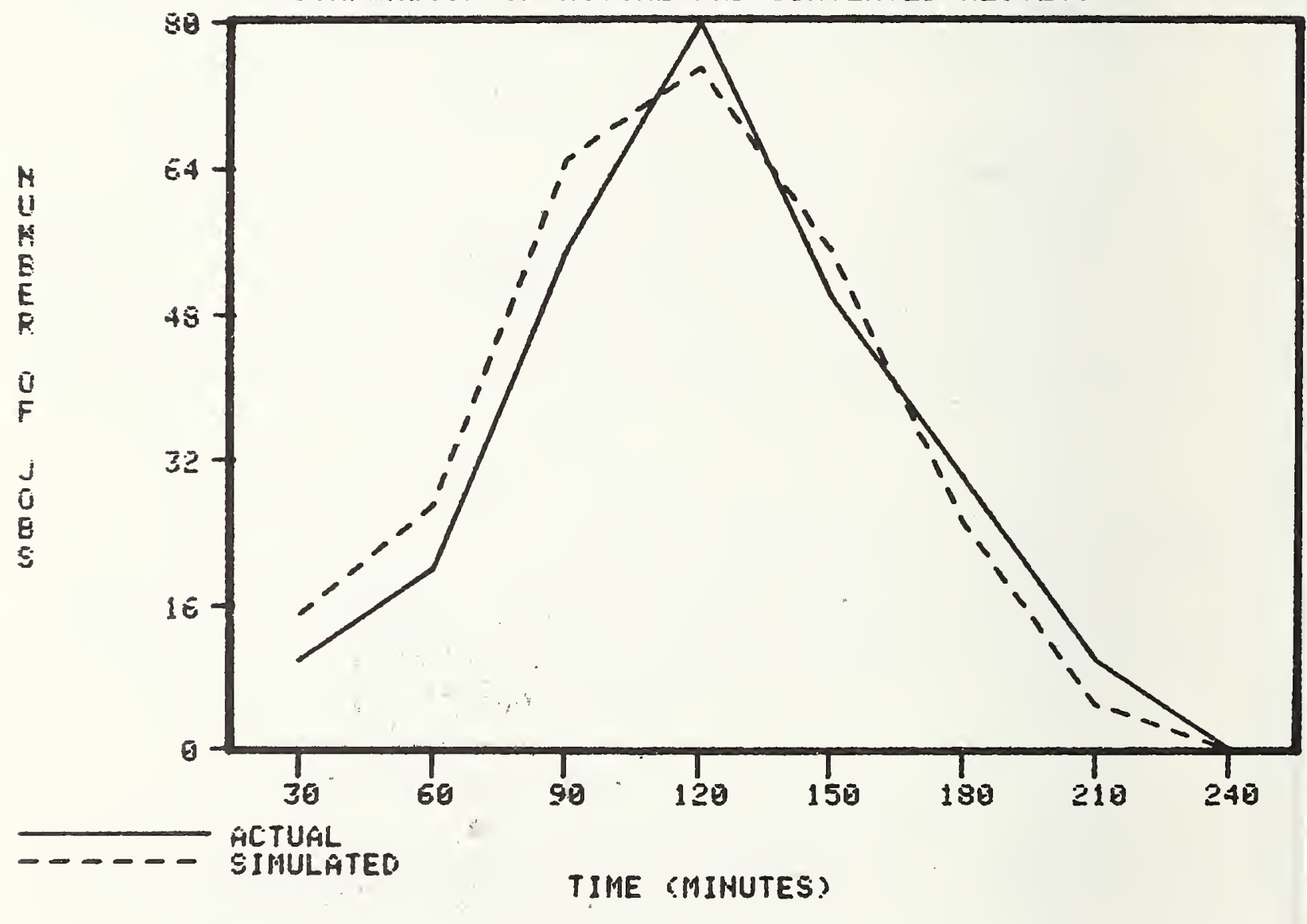

FIGURE $\quad$-5 
It is suggested that documentation for each model include the information outlined below, as part of the model documentation package. This information provides general information about the model and facilitates its possible use by others.

A. Basic Description.

1. Name or title of Model.

2. Developer ( $s$ ).

3. Agency or company.

4. Sponsor; purpose or objective of sponsor.

5. When developed?

6. Where developed?

7. Development time and cost?

8. Developed separately or as part of larger study?

B. Subject Matter of Model.

1. Major purpose of mode1.

2. Scope of mode1.

3. State basic description or theory underlying the model.

4. State specific discipline(s) required for mode 1 use, if required.

5. How does model differ from other similar mode1s?

C. Modeling Technique.

1. Describe type of model.

2. Does mode 1 use any standard packages (e.g. Iinear programming, statistical, etc.)?

3. Was the model developed from another model? If yes, describe process.

4. Is its structure clear? Its variables?

5. Describe data requirements of mode1.

6. Does model receive any data from other models?

7. What constraints are affecting the model?

D. Computer Aspects of Model.

1. In what computer language is the model written?

2. What machine (s) is it programmed for?

3. How much time does it take to run?

4. Size of model (lines of code, core to run etc.).

5. How many parameters does model require? 
E. Validation of model.

1. Has model been validated? How?

2. Has model been documented? How well?

3. Has model been critiqued or appraised? By whom? At what point?

4. Has there been a sensitivity analysis performed on the model? By whom?

5. Can the model by used from current documentation? Has it been used?

F. Model Use.

1. If asked, how would you demonstrate the utility

of the model? Have you demonstrated it?

2. With whom should one get in touch to discuss use of the model?

3. How much would it cost to transfer the model?

4. Are the model relationships or parameters easy to use for the user?

5. Have there been any papers given or written on the model? Cite references.

6. Is the output of the model special or is it designed for a general audience? 


\section{VII 。 SUMMARY}

The guidelines on the previous pages should assist in the preparation of documentation for computer models. Such documentation is primarily a tool for human communication. Varying information needs of different types of readers such as managers, model users, programmers, and analysts are accommodated. While managers are often in need of a broad spectrum of general information required for decisionmaking, users are primarily interested in practical aspects of the model and its application to the user's specific problems. Programmers require technical details which are needed for maintenance and modification of the model, while analysts are interested in the processing aspects and the underlying analytical methods and algorithms. By providing sections which have been specifically tailored to the viewpoints of diverse readers, human communications are enhanced and differing information needs are satisfied.

Users of these guidelines are requested to provide feedback on their use of this document to the authors. It would be of interest how well the document has served the user's needs, what parts have been especially useful, what parts were not used and why, and what changes or additions are suggested by the readers and users of the document. Such comments would be used in future revisions. Use of this user experience would be of great value to the Federal Modeling Community to which this paper is addressed. 


\section{B I B L I OGR A PHY}

1. Balen, N. E. "An Air Force Guide to Contracting for Software Acquisition," Bedford, MA: Mitre Corporation, January 1976 (NTIS No. AD-A020-444).

2. Comptroller General of the United States. "Ways to Improve Management of Federally Funded Computerized Models," Washington, DC: National Bureau of Standards, Department of Commerce, General Services Administration, August 23, 1976 ( LCD-75-111).

3. Connal1y, J. T. "Software Acquisition Management Guidebook: Regulations, Specifications and Standards," Bedford, MA: Mitre Corporation, October 1975 (NTIS No. AD-A016-401).

5. Control Analysis Corporation. "Draft Report TAC Warrior Analysts Manual," Palo A1to, CA: Control Analysis Corporation, 1978 .

5. Cooley, B. "Documenting Simulation Models for Management Use," Winter Simulation Conference, Gaithersburg, MD: National Bureau of Standards, December 1977.

6. Gass, Saul I. "Computer Model Documentation," Winter Simulation Conference, Gaithersburg, MD: National Bureau of St andards, December 1978 .

7. Gass, Saul I. "Computer Science and Technology: Computer Mode1 Documentation: A Review and an Approach," Washington, DC: National Bureau of Standards, Department of Commerce, February 1979 (NBS Pub. No. 500-39).

8. Hagan, S. R., et a 1. "An Air Force Guide for Monitoring and Reporting Software Development Status," Bedford, MA: Mitre Corporation, September 1975 (NTIS No. AD-A016-488).

9. Jet Propulsion Laboratory. "Software Design and Documentation Language," Pasadena, CA: National Aeronautics and Space Administration, July 1977.

10. Katzan, Harry, Jr., "Systems Design and Documentation, An Introduction to the HIPO Method," New York, NY: Van Nostrand Company, 1976.

11. Mihran, G. Arthur, "Simulation Statistical Foundations and Methodology," New York, NY: Academic Press, 1973.

12. "Study for Assessing Ways to Improve the Utility of Large-Scale Models," Palo Alto, CA: Control Analysis Corporation, 1977. 
13. Mulford, James 0 . and Jarze, Lyle R. "Critique of the TAC Turner and TAC Warrior Documentation," Washington, DC: FEDSIM, Apr 111978 .

14. Nance, Richard E. "The Feasibility of and Methodology for Developing Federal Documentation Standards for Simulation Models," Blacksburg, VA: Virginia Polytechnic Institute, June 1977 .

15. Newton, Otis L. and Weatherbee, James E. "Guidelines for Documenting Computer Simulation Models," Washington, DC: FEDSIM, October 1979 .

16. "Update 2 to Computer Program Documentation Guidelines," Washington, DC: FEDSIM, March 1979.

17. "Update 3 to Computer Program Documentation Guidelines," Washington, DC: FEDSIM, June 1979.

18. "Update 4 to Computer Program Documentation Guidelines," Washington, DC: FEDSIM, June 1979.

19. Ramapriyan, H. K., Mulford, James 0., and Jarze, Lyle R. "Evaluation of Computer Program Documentation Guideines," Washington, DC: FEDSIM, June 1978.

20. Ramapriyan, H. K. Weatherbee, James E., and Newton, otis L. "Update 1 to Computer Program Documentation Guidelines," Washington, DC: FEDSIM, January 1979.

21. Schoeffel, W. L. "An Air Force Guide to Software Documentation Requirements," Bedford, MA: Mitre Corporation, June 1976 (NTIS No. AD-A027-051). 
NBS-114A (REV. 2.8C)

U.S. DEPT. OF COMM.

BIBLIOGRAPHIC DATA

SHEET (See in structions) 1. PUBLICATION OR REPORT NO.

SP $500-73$

2. Performing Organ. Report Nof 3. Publication Date

January 1981

4. TITLE AND SUBTITLE

Computer Science and Technology:

Computer Mode1 Documentation Guide

5. AUTHOR(S)

Prepared by the Federal Computer Performance Evaluation and Simulation Center

6. PERFORMING ORGANIZATION (If joint or other than NBS, see instructions)

7. Contract/Grant No.

Federal Computer Performance Evaluation and Simulation Center

Washington, DC 20330

8. Type of Report \& Period Covered

Final

9. SPONSORING ORGANIZATION NAME AND COMPLETE ADDRESS (Street, City. State, ZIP)

Programming Science Division

Center for Programming Science and Technology

Institute for Computer Sciences and Technology

National Bureau of Standards, Washington, DC 20234

10. SUPPLEMENTARY NOTES

Library of Congress Catalog Card Number: 80-600190

[Document describes a computer program; SF-185, FIPS Software Summary, is attached.

11. ABSTRACT (A 200-word or less factual summary of most significant information. If document includes a signiflcant bibliography or literature survey, mention it here)

This document provides guidelines for preparing documentation for computer models. Recommended structures for four types of manuals providing model information for four different classes of audiences (managers, users, analysts, and programmers) is presented. This document specifies the content of sections and subsections for each type of manual. Manuals prepared using these guidelines will enable persons interested in a model to understand the capabilities and limitations of that model.

12. KEY WORDS (Six to twelve entries; alphabetical order; capitalize only proper names; and separate key words by semicolons)

Documentation; manuals; models; simulation.

13. AVAILABILITY

$[X]$ Unlimited

$\square$ For Official Distribution. Do Not Release to NTIS

[ Order From Superintendent of Documents, U.S. Government Printing Office, Washington, D.C. 20402.

Order From National Technical Information Service (NTIS), Springfield, VA. 22161
14. NO. OF

PRINTED PAGES

56

15. Price

$\$ 3.75$ 


\section{ANNOUNCEMENT OF NEW PUBLICATIONS ON COMPUTER SCIENCE \& TECHNOLOGY}

Superintendent of Documents,

Government Printing Office,

Washington, D. C. 20402

Dear Sir:

Please add my name to the announcement list of new publications to be issued in the series: National Bureau of Standards Special Publication 500.

Name

Company

Address

City State Zip Code

(Notification key N-S03) 


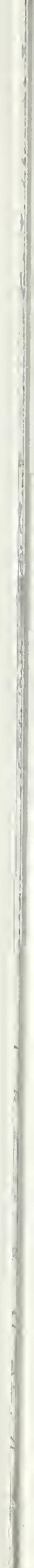




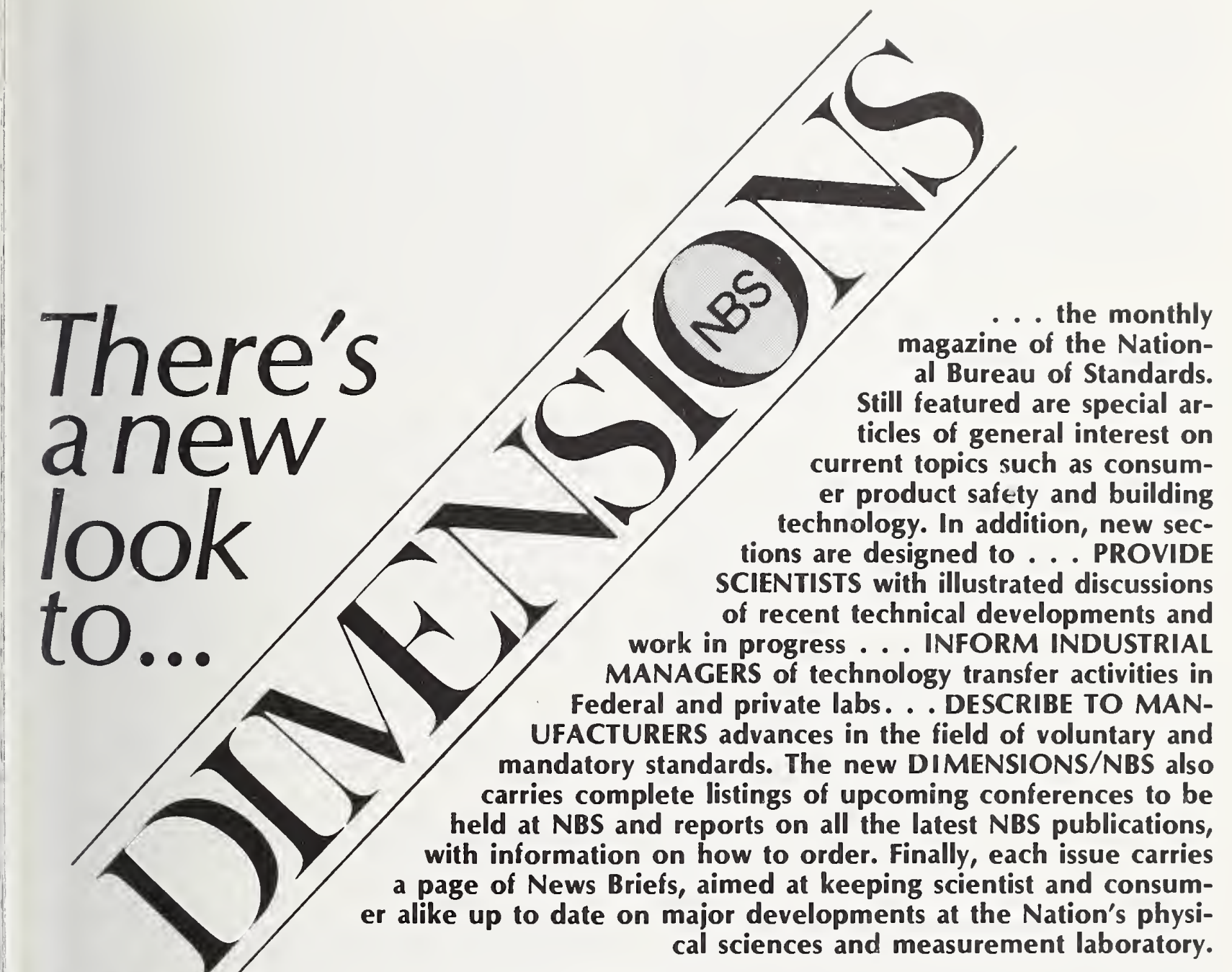

(please detach here)

BSCRIPTION ORDER FORM

2r my Subscription To DIMENSIONS/NBS at $\$ 11.00$. Add $\$ 2.75$ for foreign mailing. No additional tage is required for mailing within the United States or its possessions. Domestic remittances uld he made either by postal money order, express money order, or check. Foreign remittances uld be made either by international money order, draft on an American bank, or by UNESCO pons.

id Subscription to:

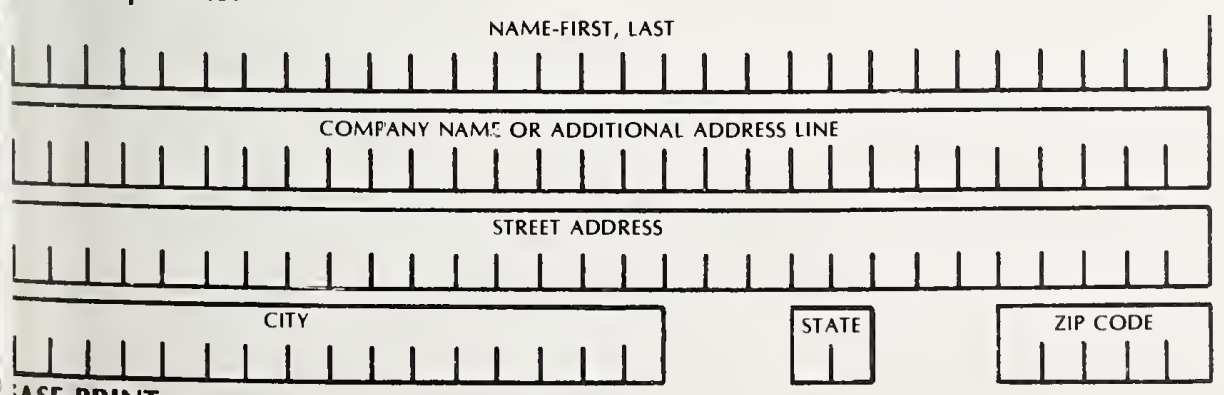

magazine of the National Bureau of Standards. Still featured are special aricles of general interest on current topics such as consumer product safety and building tions are designed to .... PROVIDE SCIENTISTS with illustrated discussions of recent technical developments and work in progress . . . INFORM INDUSTRIAL MANAGERS of technology transfer activities in Federal and private labs. . . DESCRIBE TO mandatory standards. The new DIMENSIONS/NBS also held at NBS and reports on all the latest NBS publications, with information on how to order. Finally, each issue carries cal sciences and measurement laboratory. 



\section{NBS TECHNICAL PUBLICATIONS}

\section{PERIODICALS}

JOURNAL OF RESEARCH-The Journal of Research of the National Bureau of Standards reports NBS research and development in those disciplines of the physical and engineering sciences in which the Bureau is active. These include physics, chemistry, engineering, mathematics, and computer sciences. Papers cover a broad range of subjects, with major emphasis on measurement methodology and the basic technology underlying standardization. Also included from time to time are survey articles on topics closely related to the Bureau's technical and scientific programs. As a special service to subscribers each issue contains complete citations to all recent Bureau publications in both NBS and nonNBS media. Issued six times a year. Annual subscription: domestic \$13; foreign \$16.25. Single copy, \$3 domestic; \$3.75 foreign.

NOTE: The Journal was formerly published in two sections: Section A "Physics and Chemistry" and Section B "Mathematical Sciences."

DIMENSIONS/NBS-This monthly magazine is published to inform scientists, engineers, business and industry leaders, teachers, students, and consumers of the latest advances in science and technology, with primary emphasis on work at NBS. The magazine highlights and reviews such issues as energy research, fire protection, building technology, metric conversion, pollution abatement, health and safety, and consumer product performance. In addition, it reports the results of Bureau programs in measurement standards and techniques, properties of matter and materials, engineering standards and services, instrumentation, and automatic data processing. Annual subscription: domestic \$11; foreign \$13.75.

\section{NONPERIODICALS}

Monographs-Major contributions to the technical literature on various subjects related to the Bureau's scientific and technical activities.

Handbooks-Recommended codes of engineering and industrial practice (including safety codes) developed in cosperation with interested industries, professional organizations, and regulatory bodies.

Special Publications-Include proceedings of conferences sponsored by NBS, NBS annual reports, and other special publications appropriate to this grouping such as wall charts, pocket cards, and bibliographies.

Applied Mathematics Series-Mathematical tables, manuals, and studies of special interest to physicists, engineers, chemists, biologists, mathematicians, computer programmers, and others engaged in scientific and technical work

National Standard Reference Data Series-Provides quantitative data on the physical and chemical properties of materials, com.piled from the world's literature and critically evaluated. Developed under a worldwide program coordinated by NBS under the authority of the National Standard Data Act (Public Law 90-396).
NOTE: The principal publication outlet for the foregoing data is the Journal of Physical and Chemical Reference Data (JPCRD) published quarterly for NBS by the American Chemical Society (ACS) and the American Institute of Physics (AIP). Subscriptions, reprints, and supplements available from ACS, 1155 Sixteenth St., NW, Washington, DC 20056

Building Science Series-Disseminates technical information developed at the Bureau on building materials, components, systems, and whole structures. The series presents research results, test methods, and performance criteria related to the structural and environmental functions and the durability and safety characeristics of building elements and systems.

Technical Notes-Studies or reports which are complete in themselves but restrictive in their treatment of a subject. Analogous to monographs but not so comprehensive in scope or definitive in treatment of the subject area. Often serve as a vehicle for final reports of work performed at NBS under the sponsorship of other government agencies.

Voluntary Product Standards-Developed under procedures published by the Department of Commerce in Part 10. Title 15, of the Code of Federal Regulations. The standards establish nationally recognized requirements for products, and provide all concerned interests with a basis for common understanding of the characteristics of the products. NBS administers this program as a supplement to the activities of the private sector standardizing organizations.

Consumer Information Series-Practical information, based on NBS research and experience, covering areas of interest to the consumer. Easily understandable language and illustrations provide useful background knowledge for shopping in today's technological marketplace.

Order the above NBS publications from: Superintendent of Docuinents, Government Printing Office, Washington, DC 20402.

Order the following NBS publications-FIPS and NBSIR's-from the National Technical Information Services, Springfield, VA 22161

Federal Information Processing Standards Publications (FIPS PUB)-Publications in this series collectively constitute the Federal Information Processing Standards Register. The Register serves as the official source of information in the Federal Government regarding standards issued by NBS pursuant to the Federal Property and Administrative Services Act of 1949 as amendec Public Law 89-306 (79 Stat. 1127), and as implemented by Ex ecutive Order I1717 (38 FR 12315, dated May II, 1973) and Par of Title 15 CFR (Code of Federal Regulations)

NBS Interagency Reports (NBSIR)-A special series of interim or final reports on work performed by NBS for outside sponsors (both government and non-government). In general, initial distribution is handled by the sponsor; public distribution is by the National Technical Information Services, Springfield, VA 22161, in paper copy or microfiche form. 
U.S. DEPARTMENT OF COMMERCE

Mational Bureau of Standards

Washington, O.C. 20234

POSTAGE AND FEES PAIO U.S. OEPARTMENT OF COMMERCE COM-215

OFFICIAL BUSINESS

SPECIAL FOURTH-CLASS RATE

Penalty for Private Use, $\$ 300$

BOOK 